\title{
Balancing the customization and standardization: exploration and layout surrounding the regulation of the growing field of 3D-printed medical devices in China
}

\author{
Zhongboyu Jin ${ }^{1,2} \cdot$ Chaofan $\mathrm{He}^{1,2} \cdot$ Jianzhong $\mathrm{Fu}^{1,2} \cdot$ Qianqian $\mathrm{Han}^{5} \cdot$ Yong $\mathrm{He}^{1,3,4}(\mathbb{C}$
}

Received: 7 November 2021 / Accepted: 17 January 2022 / Published online: 15 February 2022

(c) Zhejiang University Press 2022

\begin{abstract}
Medical devices are instruments and other tools that act on the human body to aid clinical diagnosis and disease treatment, playing an indispensable role in modern medicine. Nowadays, the increasing demand for personalized medical devices poses a significant challenge to traditional manufacturing methods. The emerging manufacturing technology of three-dimensional (3D) printing as an alternative has shown exciting applications in the medical field and is an ideal method for manufacturing such personalized medical devices with complex structures. However, the application of this new technology has also brought new risks to medical devices, making 3D-printed devices face severe challenges due to insufficient regulation and the lack of standards to provide guidance to the industry. This review aims to summarize the current regulatory landscape and existing research on the standardization of 3D-printed medical devices in China, and provide ideas to address these challenges. We focus on the aspects concerned by the regulatory authorities in 3D-printed medical devices, highlighting the quality system of such devices, and discuss the guidelines that manufacturers should follow, as well as the current limitations and the feasible path of regulation and standardization work based on this perspective. The key points of the whole process quality control, performance evaluation methods and the concept of whole life cycle management of 3D-printed medical devices are emphasized. Furthermore, the significance of regulation and standardization is pointed out. Finally, aspects worthy of attention and future perspectives in this field are discussed.
\end{abstract}

Keywords 3D printing $\cdot$ Medical device $\cdot$ Regulation $\cdot$ Standardization

\section{Introduction}

Qianqian Han

hanqianqian@nifdc.org.cn

$凶$ Yong $\mathrm{He}$

yongqin@zju.edu.cn

1 State Key Laboratory of Fluid Power and Mechatronic Systems, School of Mechanical Engineering, Zhejiang University, Hangzhou 310027, China

2 Key Laboratory of 3D Printing Process and Equipment of Zhejiang Province, School of Mechanical Engineering, Zhejiang University, Hangzhou 310027, China

3 Key Laboratory of Materials Processing and Mold, Zhengzhou University, Zhengzhou 450002, China

4 Cancer Center, Zhejiang University, Hangzhou 310058, China

5 National Institutes for Food and Drug Control, Beijing 102629, China

Medical devices are a class of instruments, equipment, appliances, in vitro diagnostic reagents and calibrators, materials, and other similar or related items that are directly or indirectly used in connection with humans, playing an important role in modern medical treatments [1]. Far from being a concept confined to medicine, medical devices are the embodiment of the interdisciplinary convergence of medicine, machinery, electronics, and computers. The innovation and progress in all of these disciplines promote the development of medical devices.

Interdisciplinary integration is a significant trend of current scientific research. At the intersection of medicine and engineering, three-dimensional (3D) printing, also known as additive manufacturing, whose principle is to fabricate entities by the method of layer-by-layer stacking [2, 3], has become a trending manufacturing technology. Threedimensional printing technologies provide emerging meth- 
ods for the medical field [4-7], which has resulted in the birth of the concept of "medical 3D printing" [8,9], which is now a popular research topic attracting the attention of numerous scholars. Especially, it has found applications in response to the current COVID-19 pandemic [10, 11].

According to the different aims, requirements, and methods, the mainstream applications of 3D printing in medicine can be divided into five types. (1) Physical organ models, surgical guides and in vitro medical devices. The biocompatibility requirements of their constituent materials often depend on the degree of interaction with the human body. Organ models may not have biocompatibility, but surgical guides (e.g., cutting/drill guides) and some instruments (e.g., orthodontics and prosthetics) still need biocompatibility testing. (2) Implants. Their constituent materials should be biocompatible, but not necessarily degradable. (3) Tissue scaffolds, which must be biocompatible, degradable, and absorbable. (4) In vitro tissue models. These models have biological activity and are usually constructed by biomaterials containing cells. (5) Engineered living systems.

Under the concept of "medical 3D printing," "3D-printed medical devices" has become an important direction. Among the above five types of application, "3D-printed in vitro medical devices" and "3D-printed implants" within the first two types can be classified as 3D-printed medical devices. Compared with the first two applications, in which inanimate materials like metals and polymers are predominantly used for 3D printing [12], the latter three applications often require the development of biomaterials and 3D bioprinting technologies. Limited by the current technological progress, the manufacture and application of these biologics are neither too quick nor matured, and they are mainly in the stage of research and exploration. Therefore, the application effect and regulation of 3D-printed medical devices are worthy of discussion.

Three-dimensional printing technology provides new avenues for the design and manufacture of medical devices; not only it can realize complex structures that are difficult to fabricate by traditional manufacturing methods, but also break the restrictions caused by the requirements of traditional methods for specific places, and thus realizes "manufacturing at the point of use" [13-15]. The flexibility in manufacturing in turn promotes design innovation [14], making medical devices "personalized" to match the specific situations of different patients, so as to improve the function and effect of such medical devices.

However, although 3D-printed medical devices have relatively low resource requirements for manufacturing technology and materials, this does not mean that they are easily upgraded to large-scale clinical applications. Compared to the application of 3D printing in many other fields, medical products are directly related to human life and health. Therefore, when the research of medical 3D printing yields clinical products, in order to ensure the quality, safety, and functional effect of such products, regulation is a key aspect [16]. There have been various research and application cases reflecting general concerns about the insufficient regulation of 3D-printed medical devices [4, 17-19]. Similar concerns are also reflecting the problem that the existing regulation does not necessarily keep up with the rapid advancement of additive manufacturing of medical devices [20]. Obviously, not everyone can access $3 \mathrm{D}$ printing technology to create a medical device, and not all 3D-printed medical devices are qualified and accessible. The relevant problem here is actually the lack of evaluation standards and regulatory system for 3D-printed medical devices. In recent years, some devices have been approved based on China's regulatory system, but the practical application of 3D-printed medical devices is still restricted to a small scale, which, to some extent, is due to the lagging development of regulatory work. On the one hand, for relevant government departments, there is an urgent need to establish a series of systematic and all-round regulation and evaluation systems for 3D-printed medical products, but this task is still in its infancy. On the other hand, for medical device enterprises, they may lack an understanding of the new regulations brought about by 3D printing, which leads to the confusion and fear of new technologies, or the attempt to exploit some loopholes in the new laws.

In general, the regulatory challenge of 3D-printed medical devices does not lie in the mysterious nature of 3D printing technology, but in the unique characteristics of personalization and decentralization of this manufacturing process [21]. In fact, decentralization does not necessarily bring challenges to regulation, but mainly depends on process variability. Traditional manufacturing methods have formed relatively standard and stable production modes. The parties responsible for manufacturing or the place of manufacture will not affect the relevant regulatory landscape. However, the originally stable pattern was broken by the process variability of 3D printing, which created more uncertain factors in the decentralized state of manufacturing, and led to a significant increase in the complexity of regulation. Facing these uncertainties [22,23], regulatory authorities need to use relatively unified and clear standards to evaluate personalized products, which contradiction still needs further exploration to solve (Fig. 1).

This review aims to discuss the recent status and progress of 3D-printed medical device regulation and standardization in Mainland China. In addition, it emphasizes the quality control points and the whole life cycle management of 3D-printed medical devices and provides insights into the current challenges in this field. To avoid confusion and clarify the subject of this review, the 3D-printed medical devices discussed here are mainly personalized or customized devices rather than mass-produced 3D-printed devices, and do not include 3D-bioprinted medical products 
Fig. 1 Characteristics and regulatory considerations of additively manufactured medical devices

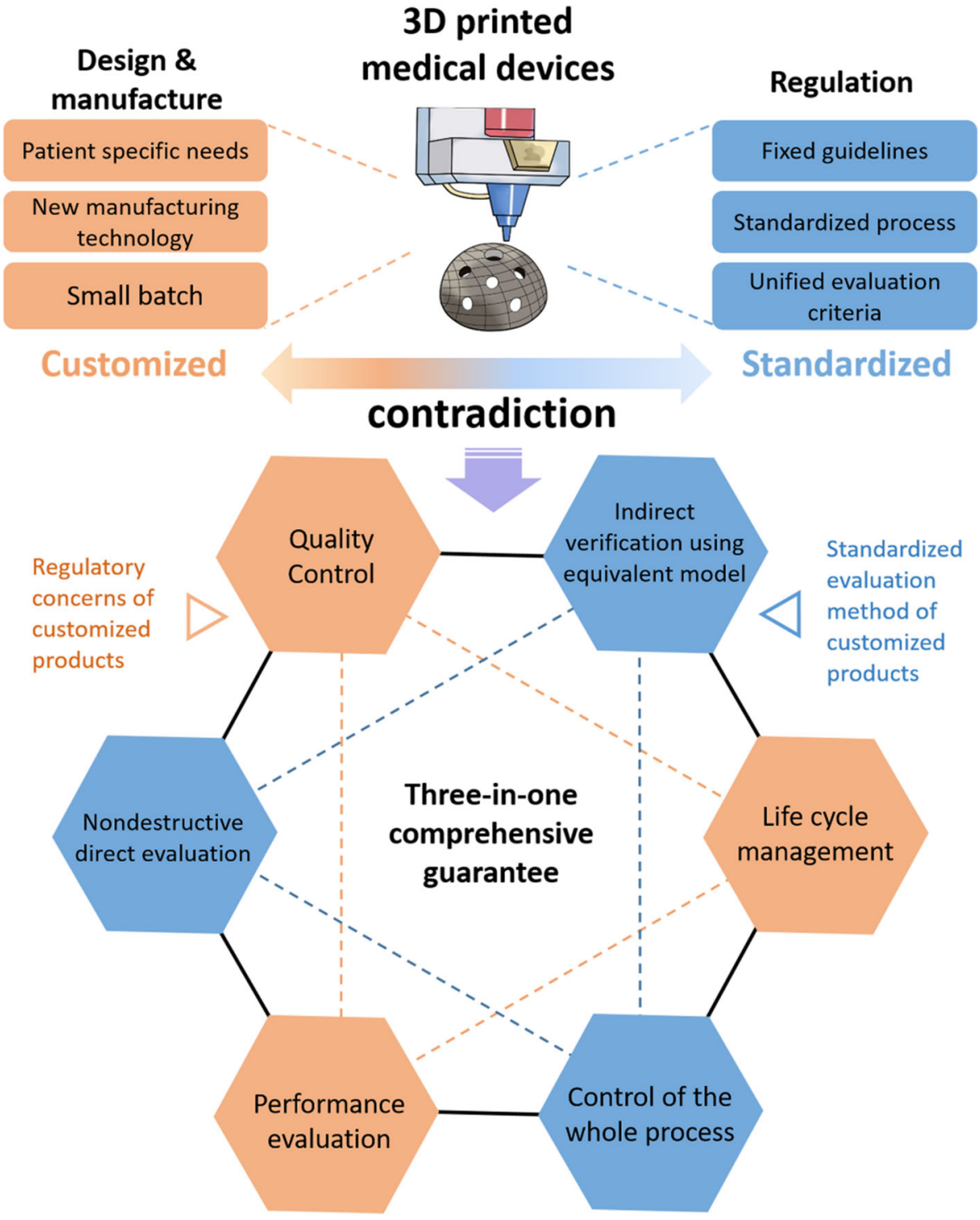

and 3D-printed drugs. This does not mean that the regulation of 3D-printed personalized devices has no relationship with that of other types of products. Instead, the exploration and construction of the regulatory system of various products are based on mutual reference and complement each other. As the main subject of this review, we focus on three points: (1) The different concerns of the regulatory authorities in 3D-printed medical devices; (2) The quality system of 3Dprinted medical devices and its importance; (3) The future development direction of standardization work on 3D-printed medical devices.

More specifically, this review outlines the requirements and challenges of the regulation and standardization of 3Dprinted medical device products, followed by a detailed introduction of the development process of relevant work in China, mainly including the existing regulations, standards and guidance system, as well as the follow-up research layout. Next, we emphatically discuss the focal point of 3Dprinted medical device regulation, concentrating on the two key words of quality control and performance evaluation, and then describing the details. Then, we examine the importance and current limitations of regulation and standardization. Finally, our perspective on the future directions is presented. We hope that this review can assist medical device enterprises with making a better use of 3D printing technology to manufacture innovative products that meet the regulatory requirements, and thus obtain regulatory approval more easily to realize the application value of such products. 


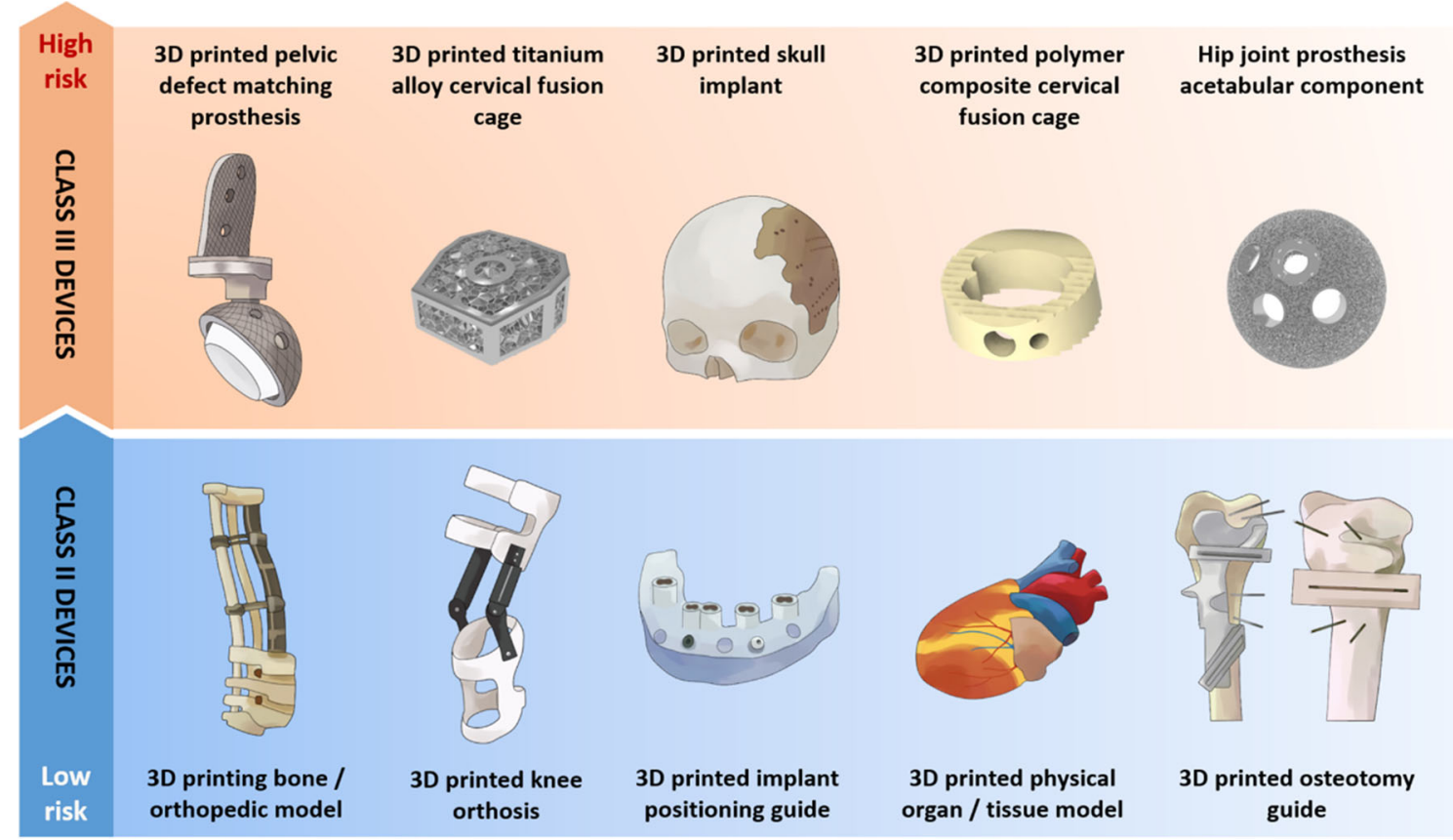

Fig. 2 Simplified diagrams of representative types of 3D-printed medical devices that have been certified

\section{Standardization and quality system of 3D-printed medical devices in China}

Recently, the application of additive manufacturing technology in the process of medical device design and manufacturing has opened up exciting opportunities for the innovation and development of medical devices. Three-dimensional printing technology is not only developing rapidly, but also cross-integrates the needs of biomedical materials, engineering, informatization, and medical individualization. Therefore, it has been more commonly used in the past five years. The types of products involved in these applications include medical models, surgery guide plates, orthopedic products, tissue repair products, vascular implants, orthopedic appliances, and so on. Various types of products have been approved by regulatory authorities around the world (Fig. 2). The key advantage of 3D-printed medical devices is that they can achieve precisely fabricated microstructure and personalized customization. In addition, they can greatly expand the innovation of product design, improve product performance, shorten the development cycle, improve manufacturing efficiency, and reduce material consumption [14, $24,25]$. Various impressive attempts have been reported to successfully produce medical devices using $3 \mathrm{D}$ printing technology, reflecting their positive impact on clinical treatment $[8,19,26]$. However, new technologies also bring additional risks that cannot be ignored, as well as new challenges for regulatory work. Since customized medical devices are designed according to the individual needs of patients, these products are different and smaller in quantity, and it is impossible to carry out preclinical experimental research and clinical trials in accordance with the sample size requirements of standardized medical devices. Therefore, regulations and registration systems applicable to standardized medical devices are no longer fully applicable to such customized medical device products [24]. The development of this field urgently requires the guidance of risk analysis and quality control techniques, as well as standardization efforts.

A large number of regulatory agencies and scientific research institutions around the world have been actively exploring methods of standardization. As a result of these efforts, many countries have issued regulatory regulations and guidance documents on customized additively manufactured medical device products. The regulatory systems presented by these countries and organizations have been systematically reviewed and analyzed previously [21, 27], therefore, will not be detailed here, but only some selected examples will be introduced. Take the USA and the European Union as examples. As early as 1976, the US FDA enacted the "Food, Drug and Cosmetic Act" amendment, which first proposed the concept of a custom-made device. It is worth noting that on December 5, 2017, the FDA officially released the "Technical Considerations for Additive-Manufactured Medical Devices" [28]. This guide is based on the additive manufacturing process flowchart, expounding the technical factors that need to be considered for additive manufacturing of medical devices from the aspects of 3D printing design to software workflow, material control, post-processing, and 
testing considerations [29]. To date, 3D-printed medical devices listed in the USA have been mainly reviewed and regulated according to the pre-market notification $(510(\mathrm{k}))$ and new drug application (NDA) pathways [16]. On the other hand, the "Guidance Note For Manufacturers of Custommade Medical Devices" [30] was issued by the European Union on November 11, 2009, which describes the necessary steps for the launching of custom-made medical devices and the concerns in each step. With regard to international organizations, the IMDRF (International Medical Device Regulators Forum) is a notable non-profit organization formed by the medical device regulatory authorities of China, the USA, the European Union, Canada, Australia, and other countries and regions [31]. This group established the Personalized Medical Device Working Group in September 2017 to conduct research on the terminology and regulatory requirements of personalized medical devices, and officially released the "Guidance of Personalized Medical Device Terms" guide in September 2018. Therein, according to the degree of personalization from high to low, medical devices were divided into Custom-made Devices, Patientmatched Medical Devices, and Adaptable Medical Devices, thus forming an internationally used personalized medical device terminology and classification [32, 33]. Meanwhile, it should be noted that not only special regulations are applicable to 3D-printed medical products, but also standards and specifications are implemented for general medical devices and 3D printing technologies [34]. The examples are only tips of the iceberg, which can also indicate the increasing attention paid to the standards and regulation of 3D-printed personalized medical devices.

As far as Mainland China is concerned, the exploration and clinical application of personalized medical devices began in the 1990s. Since 2002, regulatory requirements for customized dentures have been successively introduced [32]. However, the lack of relevant standards for 3D-printed medical devices and the lag in regulatory work in the early stage remain major problems in the industrial development and clinical application of additive manufacturing. In recent years, the Chinese medical device regulatory agency has carried out a series of works combining foreign regulatory experience and national conditions, which has greatly improved the early issues. Meanwhile, the medical device industry association has also established a professional committee for additively manufactured medical devices, which not only serves as an interactive communication platform for medicine and engineering, but also it continuously organizes the formulation of 3D-printed medical device group standards, and jointly promotes the rapid development of medical device standardization research and supervision in China by regulatory authorities. With the joint efforts of all walks of life, China's medical device standardization research and regulatory work have achieved rapid progress.
In 2014, orthopedic implants that were additively manufactured using selective laser melting (SLM) technology were listed in the "Class III Medical Devices Subject to Clinical Trial Approval" in China [35]. Then, in February 2015, 3D-printed medical devices were listed as one of the development priorities of the "National plan for promoting the development of additive manufacturing industry (2015-2016)" [36]. Subsequently, on November 30, 2017, the Ministry of Industry and Information Technology of the People's Republic of China and twelve departments jointly formulated the "Action plan for the development of additive manufacturing industry (2017-2020)" [37] to further promote the rapid development of China's additive manufacturing industry, in which the model of "3D printing + medicine" that involves a series of products including personalized medical devices has become one of the exemplary application directions. With the determination of the above development priorities, a series of regulatory work has been gradually carried out. On February 26, 2018, the Center for Medical Device Evaluation of China National Medical Products Administration issued the "Guidelines for the Technical Review of the Registration of Customized Additive Manufacturing Medical Devices" [38], which aims to encourage the innovative development of medical devices, provide technical guidance for applicants in the registration and application of customized additive-manufactured medical device products, and supply a technical reference for the review of registration and application of materials by the food and drug administration department. The Chinese "Regulations on the Management of Customized Medical Devices (trial)" [39] was officially released on July 4, 2019, which put forward corresponding requirements in terms of records management, design and processing, utility management, supervision, and set out the requirements and instructions for the record data of customized medical devices, in order to provide technical guidance for the filing of such medical device products [24]. More importantly, this regulation designates a path for the clinical application of 3D printing for rare diseases and adopts a filing system for corresponding customized medical device products. That is, the pre-market filing management is adopted to meet the urgent clinical needs, and when the number of clinical application cases and preliminary research of these medical devices can meet the pre-market approval requirements, the registration management will be implemented [24]. Similar special regulatory considerations for customized medical devices for rare diseases, which do not mean lack of regulation, are common in the laws and regulations of some other countries and regions, also known as "exemption" [40]. The promulgation of this regulation marks a new era in China's regulation of personalized medical devices [32].

In addition to regulatory regulations, the "Guidelines for the Technical Review of the Registration of Passive 


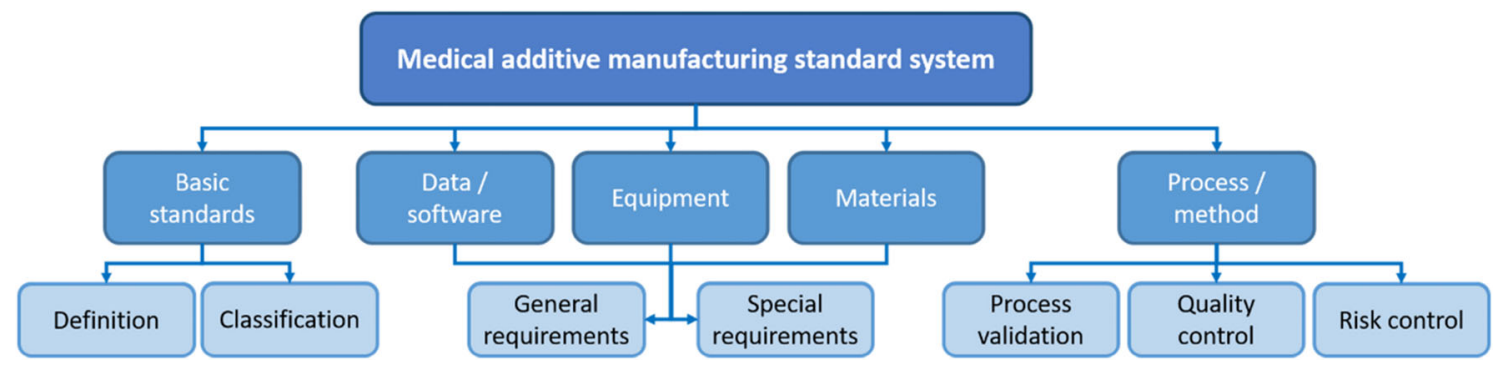

Fig. 3 China's current medical additive manufacturing standard system

Implantable Bone, Joint and Oral Hard Tissue Personalized Additive Manufacturing Medical Devices (No. 70 of 2019)" [41] was issued on September 23, 2019. The formulation of this guiding principle is based on the risk identification and control of customized additively manufactured medical devices, and it runs through the entire life cycle of medical devices. Under the premise of risk control, the necessary supervision is adjusted beforehand, supervision is strengthened during and after the fact, the inherent laws of customized additively manufactured medical devices are reflected, and the innovation of regulation theory and system are emphasized to realize the scientific supervision of medical devices [24]. This technical document is China's first of its kind for the personalized design and additive manufacturing of medical devices, which comprehensively proposes specific technical problems and basic solutions for personalized hard tissue implant devices; therefore, it has an important guiding role for research, development and production. Besides, it also provides a reference for the subsequent establishment of relevant guiding principles [32].

The importance of regulations and guidelines is selfevident; however, they are not created independently or in a vacuum, but are based on a series of scientific research on 3D-printed medical devices. The ideal regulatory work should be a system of mutual cooperation with the study of standardized content as an important aspect, rather than relying solely on regulations.

With the expansion of the application scope of additive manufacturing and the increasing attention paid to 3D-printed medical devices, the attention of China's regulatory authorities on this field has increased significantly. The China National Medical Products Administration (NMPA) has formed a set of industry standards for the traditional medical industry, and the relevant subordinate industry standards have corresponding 24 standardization technical committees. After realizing the application potential of 3D printing in the medical field, the China National Institutes for Food and Drug Control (NIFDC) under the NMPA has actively applied since 2014 for the establishment of a focal point for the 3D-printed medical device industry standards to undertake the formulation of these standards. In December 2017, the NIFDC established a medical additive manufacturing standards working group to carry out research on the standardization of 3D-printed medical devices and formulate plans for industry standards. Then, in October 2019, a centralized unit of NMPA for medical additive manufacturing technology and medical device standardization technology was formally established. At the beginning, a total of 40 experts formed a focal unit expert group, with delegates from regulatory agencies, testing agencies, clinical institutions, and manufacturing companies, covering all stakeholders that may be involved.

To date, a medical additive manufacturing standard system has been formed, which mainly focuses on generality and fundamentality (Fig. 3). This standard system covers five aspects, including raw materials, process verification methods, equipment, data transmission, and risk management, and attention is paid to the entire process chain of additive manufacturing technology. Through applying advanced standards, the foundations of quality control in the industry were laid. In addition, the NIFDC has formulated two basic raw material industry standards and two process verification standards for materials, processes, and methods. Three of these standards have been published (Table 1). Specifically, these mainly involve the technical index requirements and standards of medical additive manufacturing powder metal raw materials, product application risk assessment method standards, and manufacturing process verification method standards, which can be used as bases for research, development and production, and the standard for review and regulation.

It is also noteworthy that industry associations are an important bridge and tie between regulatory authorities and enterprises. They are not a government agency, but also an important force that regulates the industry and leads its development. In January 2017, the China Association for Medical Devices Industry established the Additive Manufacturing Medical Devices Committee (AMMDC), which is mainly composed of member units of additive manufacturing-related materials, software, design, and application services, as well as experts in the fields of medicine and engineering [42]. During the development of standardization of 3D-printed medical devices in recent years, AMMDC has drafted and 
Table 1 The basic raw material industry standards and process verification standards formulated by NIFDC

\begin{tabular}{|c|c|c|c|c|c|}
\hline & $\begin{array}{l}\text { Standard system draft } \\
\text { number }\end{array}$ & Category & Standard number & Standard name & Current stage \\
\hline 1 & $4-02$ & $\begin{array}{l}\text { Material-specific } \\
\text { requirements }\end{array}$ & YY/T1701-2020 & $\begin{array}{l}\text { Medical Grade } \\
\text { Ti-6Al-4 V/Ti-6Al-4 V } \\
\text { ELI Powder Used for } \\
\text { Additive } \\
\text { Manufacturing }\end{array}$ & $\begin{array}{l}\text { Officially implemented } \\
\text { on June } 1,2021\end{array}$ \\
\hline 2 & $5-01$ & $\begin{array}{l}\text { Process verification } \\
\text { requirements }\end{array}$ & $\begin{array}{l}\text { N2020006-T-ZJY } \\
\text { (project) }\end{array}$ & $\begin{array}{l}\text { Validation Method of } \\
\text { Cleaning Effect of } \\
\text { Metal Powder in } \\
\text { Medical Additive } \\
\text { Manufacturing } \\
\text { Powder-bed Fusion } \\
\text { Process }\end{array}$ & $\begin{array}{l}\text { Submitted for approval } \\
\text { in December } 2020\end{array}$ \\
\hline 3 & $4-02$ & $\begin{array}{l}\text { Material-specific } \\
\text { requirements }\end{array}$ & $\begin{array}{l}\text { N2021008-T-zjy } \\
\text { (project) }\end{array}$ & $\begin{array}{l}\text { Medical Pure Tantalum } \\
\text { Powder for Additive } \\
\text { Manufacturing }\end{array}$ & Being formulated in 2021 \\
\hline
\end{tabular}

issued a series of group standards based on the current situation of the industry and market. The first batch of group standards was issued in June 2019, including five group standards, which put forward standards on the equivalent mechanical model of customized medical devices, special requirements for the quality system, the product realization process under the condition of Internet, and the whole process specification of medical-engineering interaction [43]. Subsequently, AMMDC issued the second batch (10 items in total) [44] and the third batch (15 items in total) [45] of group standards in June 2020 and August 2021, respectively. The coverage of standards is gradually widening from the material analysis, testing and evaluation standards of medical additive manufacturing to the standards of various kinds of 3D-printed medical devices, such as joint prosthesis, bone defect filler, scoliosis orthosis, and so on. Furthermore, the drafting of the fourth batch of group standards is still in progress. The formulation of these group standards fills the current need for standardization work from a professional perspective, provides guidance for medical device manufacturers, and significantly promotes the standardization of the field of 3D-printed medical devices (Table 2).

With the implementation of the above-mentioned regulations, guiding principles, and standardization work, a growing body of 3D-printed medical devices has been approved. By April 2021, a total of 11 3D-printed medical devices have been certified by the NMPA in Mainland China, as shown in Table 3. Among these approved devices, there are both customized and non-customized ones. In other words, not all 3Dprinted medical devices are customized or patient-matched. In terms of functional classification, these devices can also be classed into a variety of categories, including physical organ models (e.g., 3D-printed bone models, tissue models), surgical guides (e.g., 3D-printed osteotomy guides), orthoses (e.g., 3D-printed orthodontic orthoses, articular orthoses), all of which belong to class II medical devices. Meanwhile, class III medical devices are represented by orthopedic implant products. In addition to the concepts of class II and III, there are also class I medical devices (not mentioned here), which are all pre-market classifications of medical devices based on their risks and the level of control necessary to ensure their safety and efficacy. This is also a globally applied universal classification principle [27, 47]. Class I devices have the lowest risk, while class III devices are considered as the highest-risk, and thus are subject to different levels of regulation. Although the categories and functions are diverse, they all show that 3D printing provides two major advantages for medical devices [48]: creating patient-matched devices, and allowing for complex architectures.

In general, like in many countries and regions in the world, the development of regulatory and standardization work of additively manufactured medical devices in China can also be summarized as "crossing the river by feeling the stones." Despite that the global concept of customized medical devices has been proposed by regulations more than 40 years ago, 3D-printed medical devices are still an emerging topic and research direction for all involved countries. The scientific research targeting 3D-printed medical devices continues to be in a stage of vigorous development. At the same time, the regulatory authorities are constantly accumulating experiences, and the relevant regulations and standards will be gradually improved. Finally, research and regulation act together to promote the role of future 3D-printed medical devices in the clinic. 
Table 2 Common national regulations and industry standards for regulating 3D-printed medical devices in China

\begin{tabular}{|c|c|c|c|c|}
\hline Attribute & Category & Name & Number & Reference \\
\hline \multirow[t]{19}{*}{$\begin{array}{l}\text { Group standard (issued by } \\
\text { organizations) }\end{array}$} & \multirow[t]{15}{*}{ Product requirements } & $\begin{array}{l}\text { Personalized artificial } \\
\text { temporomandibular joint }\end{array}$ & T/CAMDI 027-2019 & [43] \\
\hline & & $\begin{array}{l}\text { Additively manufactured } \\
\text { (3D-printed) metal dental } \\
\text { implant }\end{array}$ & T/CAMDI 044-2020 & \multirow[t]{4}{*}{ [44] } \\
\hline & & $\begin{array}{l}\text { Additive manufacturing (3D } \\
\text { printing) of custom-made dental } \\
\text { implant }\end{array}$ & T/CAMDI 043-2020 & \\
\hline & & $\begin{array}{l}\text { Additive manufacturing ( } 3 \mathrm{D} \\
\text { printing) of customized guide } \\
\text { plates for orthopedic surgery }\end{array}$ & T/CAMDI 041-2020 & \\
\hline & & $\begin{array}{l}\text { Additive manufacturing (3D } \\
\text { Printing) of dental implant } \\
\text { surgical guides }\end{array}$ & T/CAMDI 038-2020 & \\
\hline & & $\begin{array}{l}\text { Personalized additive } \\
\text { manufacturing occlusal splint }\end{array}$ & T/CAMDI 063-2021 & \multirow[t]{10}{*}[45]{} \\
\hline & & $\begin{array}{l}\text { Additive manufacturing of } \\
\text { tantalum hip joint prosthesis }\end{array}$ & T/CAMDI 064-2021 & \\
\hline & & $\begin{array}{l}\text { Additive manufacturing of } \\
\text { tantalum knee joint prosthesis }\end{array}$ & T/CAMDI 065-2021 & \\
\hline & & $\begin{array}{l}\text { Additive manufacturing of } \\
\text { customized tantalum bone } \\
\text { defect filler }\end{array}$ & T/CAMDI 066-2021 & \\
\hline & & $\begin{array}{l}\text { Additive manufacturing of } \\
\text { tantalum spinal prosthesis }\end{array}$ & T/CAMDI 067-2021 & \\
\hline & & $\begin{array}{l}\text { Additive manufacturing of auricle } \\
\text { pressure orthotic device }\end{array}$ & T/CAMDI 068-2021 & \\
\hline & & $\begin{array}{l}\text { Additively manufactured } \\
\text { patient-matched wrist-hand } \\
\text { orthoses }\end{array}$ & T/CAMDI 069-2021 & \\
\hline & & $\begin{array}{l}\text { Customized additively } \\
\text { manufactured } \\
\text { polyetheretherketone (PEEK) } \\
\text { craniomaxillofacial implants }\end{array}$ & T/CAMDI 070-2021 & \\
\hline & & $\begin{array}{l}\text { Personalized metal additive } \\
\text { manufacturing of chest wall } \\
\text { deformity orthosis device }\end{array}$ & T/CAMDI 071-2021 & \\
\hline & & $\begin{array}{l}\text { Customized additively } \\
\text { manufactured scoliosis orthosis }\end{array}$ & T/CAMDI 072-2021 & \\
\hline & \multirow[t]{4}{*}{ Evaluation and analysis methods } & $\begin{array}{l}\text { Mechanical equivalent model of } \\
\text { customized medical devices }\end{array}$ & T/CAMDI 025-2019 & \multirow[t]{4}{*}[43]{} \\
\hline & & $\begin{array}{l}\text { Special requirements for quality } \\
\text { system of customized medical } \\
\text { devices }\end{array}$ & T/CAMDI 026-2019 & \\
\hline & & $\begin{array}{l}\text { General requirements for internet } \\
\text { implementation conditions of } \\
\text { custom additively manufactured } \\
\text { (3D-printed) medical devices }\end{array}$ & T/CAMDI 028-2019 & \\
\hline & & $\begin{array}{l}\text { Determination index and } \\
\text { acceptance condition and the } \\
\text { whole process monitoring of } \\
\text { medical and industry interaction } \\
\text { of customized medical device }\end{array}$ & T/CAMDI 029-2019 & \\
\hline
\end{tabular}


Table 2 continued

\begin{tabular}{|c|c|c|c|c|}
\hline Attribute & Category & Name & Number & Reference \\
\hline & & $\begin{array}{l}\text { Evaluation method and criterion } \\
\text { of quality uniformity of } \\
\text { 3D-printed metal implants }\end{array}$ & T/CAMDI 046-2020 & [44] \\
\hline & & $\begin{array}{l}\text { Finite element analysis of } \\
\text { 3D-printed metal implants }\end{array}$ & T/CAMDI 045-2020 & \\
\hline & & $\begin{array}{l}\text { Special requirements for quality } \\
\text { management system for metal } \\
\text { additively manufactured } \\
\text { medical devices }\end{array}$ & T/CAMDI 040-2020 & \\
\hline & & $\begin{array}{l}\text { Bioprinting medical } \\
\text { devices-special requirements } \\
\text { for quality management system }\end{array}$ & T/CAMDI 039-2020 & \\
\hline & & $\begin{array}{l}\text { Test standard for fatigue } \\
\text { performance of additive } \\
\text { manufacturing femoral stem }\end{array}$ & T/CAMDI 060-2021 & {$[45]$} \\
\hline & & $\begin{array}{l}\text { Standard for evaluating the } \\
\text { biological hazards of residual } \\
\text { particles in additively } \\
\text { manufactured metal implant }\end{array}$ & T/CAMDI 061-2021 & \\
\hline & & $\begin{array}{l}\text { Special requirements for 3D } \\
\text { modeling software in additively } \\
\text { manufactured personalized } \\
\text { medical devices }\end{array}$ & T/CAMDI 062-2021 & \\
\hline & Materials and equipment & $\begin{array}{l}\text { Powder bed electron beam } \\
\text { additive manufacturing } \\
\text { equipment for medical devices }\end{array}$ & T/CAMDI 073-2021 & \\
\hline & & $\begin{array}{l}\text { Clinical application standard of } \\
\text { 3D-printed tantalum }\end{array}$ & T/CAMDI 037-2020 & {$[44]$} \\
\hline & & $\begin{array}{l}\text { Biomedical tantalum powder } \\
\text { used for additive manufacturing }\end{array}$ & T/CAMDI 042-2020 & \\
\hline & & $\begin{array}{l}\text { Control standard for reuse of } \\
\text { medical metal powder of } \\
\text { additive manufacturing }\end{array}$ & T/CAMDI 059-2021 & {$[45]$} \\
\hline \multirow[t]{5}{*}{$\begin{array}{l}\text { National regulations and } \\
\text { guidelines (issued by } \\
\text { regulators) }\end{array}$} & \multirow[t]{3}{*}{ Guidelines } & $\begin{array}{l}\text { Guidelines for the technical } \\
\text { review of the registration of } \\
\text { passive implantable bone, joint } \\
\text { and oral hard tissue as } \\
\text { personalized additively } \\
\text { manufactured medical devices } \\
\text { (No. } 70 \text { of 2019) }\end{array}$ & - & [41] \\
\hline & & $\begin{array}{l}\text { Guidelines for the technical } \\
\text { review of the registration of } \\
\text { customized additively } \\
\text { manufactured medical devices }\end{array}$ & & [38] \\
\hline & & $\begin{array}{l}\text { Guidelines for the technical } \\
\text { review of the registration of } \\
\text { equivalence models of } \\
\text { customized personalized bone } \\
\text { implants }\end{array}$ & & {$[46]$} \\
\hline & \multirow[t]{2}{*}{ Regulations } & $\begin{array}{l}\text { Regulations on the management } \\
\text { of customized medical devices }\end{array}$ & & [39] \\
\hline & & $\begin{array}{l}\text { Class III medical devices subject } \\
\text { to clinical trial approval }\end{array}$ & & {$[35]$} \\
\hline
\end{tabular}




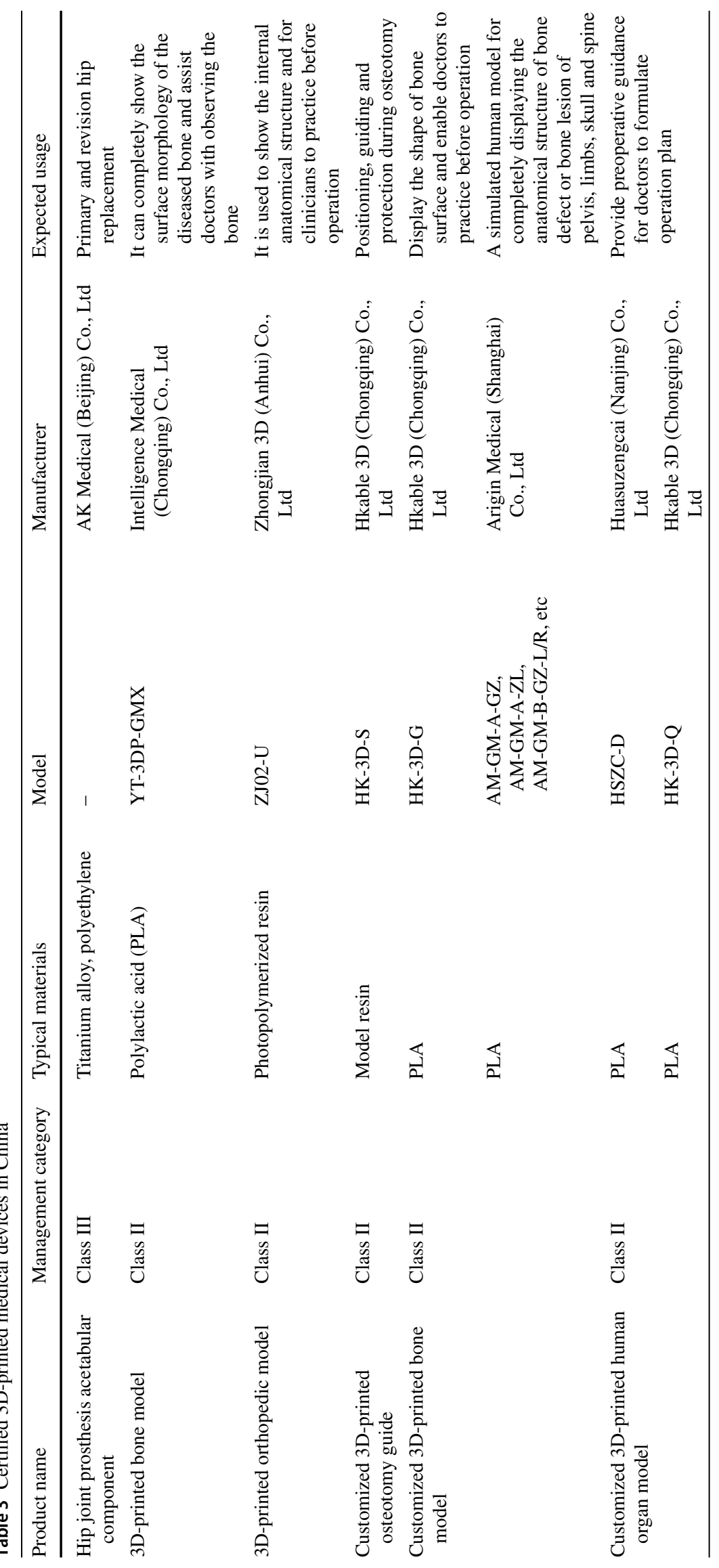




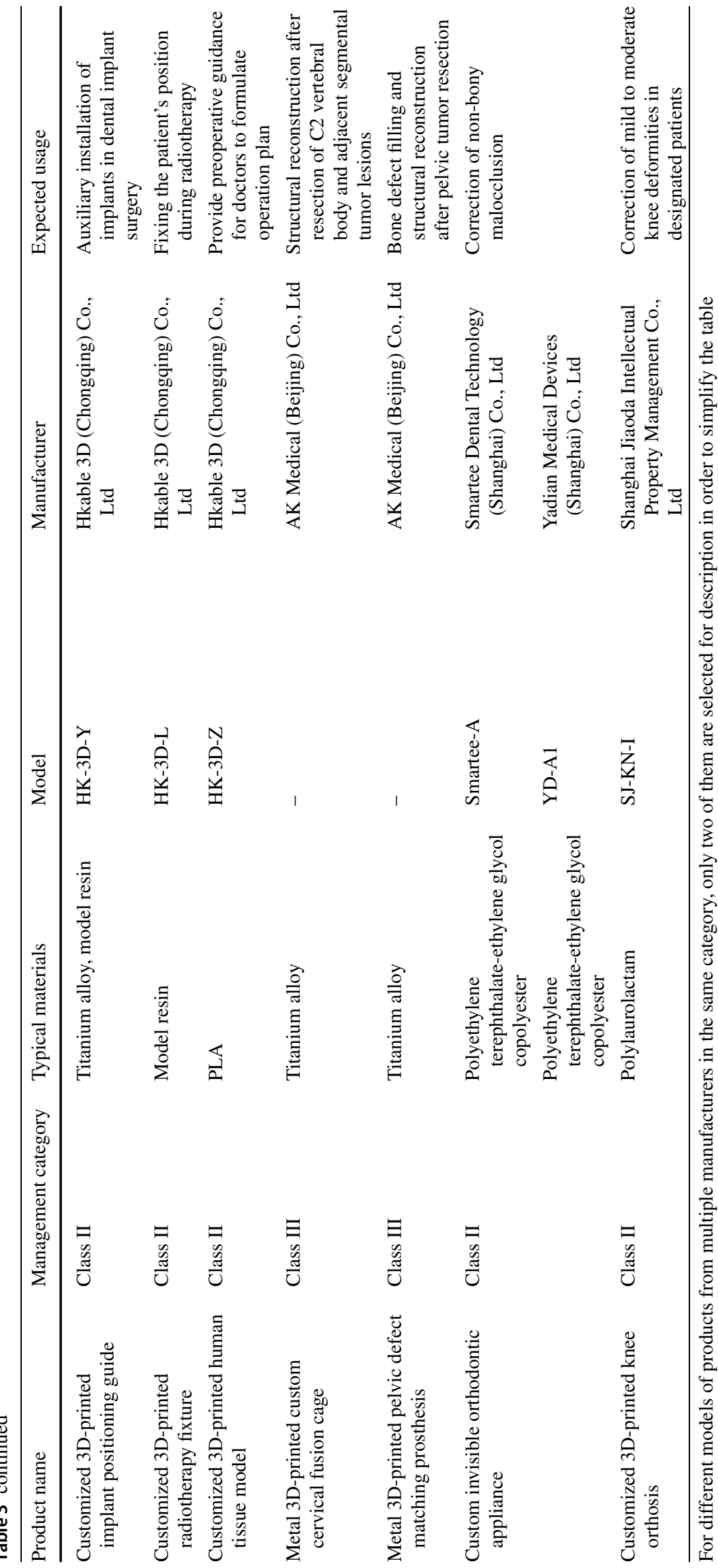




\section{Quality control of the manufacturing process and its key points}

For the implementation of 3D-printed medical device products, safety is the most important aspect [15]. Both safety and effectiveness are measures of product performance evaluation. Obviously, to ensure product performance, especially the long-term safety of implant products after implantation, it is not sufficient to test and evaluate the products after their manufacture, but it is necessary to control each link from the early design and manufacturing stage, thus forming the concept of product quality control. In the quality control stage, the highest-priority task is to carry out the risk analysis of each link of manufacture, and to identify the risks the new technology may bring. Since the principle of 3D printing and the form of materials used are completely different from traditional manufacturing technologies, such as casting, forging, and pouring processes, the use of 3D printing technology may present additional risks and challenges in terms of the manufacturing control, performance, biocompatibility, and sterilization of medical device products [48], and thus greatly increase the number of factors to be considered in quality control. In addition to the risks caused by the processing methods, the lack of understanding of the quality control process by medical-engineering interaction personnel [49], and the mismatch between the progress of additive manufacturing standardization and the needs of industrial development both increase the risks of additively manufactured products. It can be seen that "risk" and "quality" are the two keywords that people first pay attention to when evaluating the performance of 3D-printed medical devices. On this basis, two key types of quality control of 3D-printed medical devices were developed: "whole process quality control" and "whole life cycle risk management," which promoted the urgent need to standardize additive manufacturing in this field.

The quality control of additively manufactured medical devices involves many links in the manufacturing process and production management, such as medical-engineering interaction, raw material quality control, printing equipment management, processing parameters, post-processing management and finished product quality control, as shown in Fig. 4. These links have not only formed diverse quality control concepts [49], but also have different key points. In this section, we introduce these quality control points, and focus on raw material quality control, process verification and product application risk assessment for 3D-printed medical devices.

\section{Medical-engineering interaction}

The application of additive manufacturing in the field of medical devices does not simply change the manufacturing process, but forms a complex and unique medical-engineering interaction [50], and its participating roles include "medical roles" (medical institutions and their clinicians engaged in the clinical application of customized and patient-matched medical devices) and "engineering roles" (enterprises engaged in medical image data processing, and the design, development and production of customized and patient-matched medical devices, and their engineering technicians and production managers) [51].

Different from non-customized medical devices, medical-engineering interaction is one of the salient features of patient-matched 3D-printed medical devices, which is reflected in many workflows, including clinical diagnosis, medical image data operation, design and development, and production [51]. As the first step, data and modeling work is a typical embodiment of medical-engineering interaction, and it is the basis for the implementation of many subsequent steps. Doctors need to make judgments based on the clinical needs of patients and device applicability, while accurately obtaining clinical data, which is the prerequisite for modeling. Engineers and technicians realize a reasonable design according to the clinical data collected. On the one hand, reasonable design is the key to the realization of the printing process. On the other hand, the design stage includes the formulation of product shape and internal microstructure, and having a complex internal microstructure is one of the advantages of 3D-printed medical devices. Besides, the verification of these data and the software used to operate these data is also the key point of quality control. The compatibility of the software, and the correctness and integrity of data conversion shall be verified. The worst case shall be selected to test all document conversion processes to ensure the expected performance. The name and version number of the software used shall also be specified [52].

The complexity of the above process and the diversity of medical-engineering interaction roles make this process affected by many uncertain factors [51]. Therefore, the concept of medical-engineering interaction runs through the entire process of development, application, and quality control of additive manufacturing medical device products, in which the process standardization, the effectiveness of interactive information, close collaborations, and welldocumented files are of great importance [18]. To realize the manufacturing, quality control, and supervision of personalized medical devices, it is essential to firstly accurately define the key links and their constituent elements of the whole process of medical-engineering interaction, and study the means to effectively control these elements [51].

The significance of medical worker interaction requirements has also been reflected in the main guiding principles in recent years. For instance, the "Guidelines for the Technical Review of the Registration of Passive Implantable Bone, Joint and Oral Hard Tissue Personalized Additive Manufacturing Medical Devices (No. 70 of 2019)" speci- 


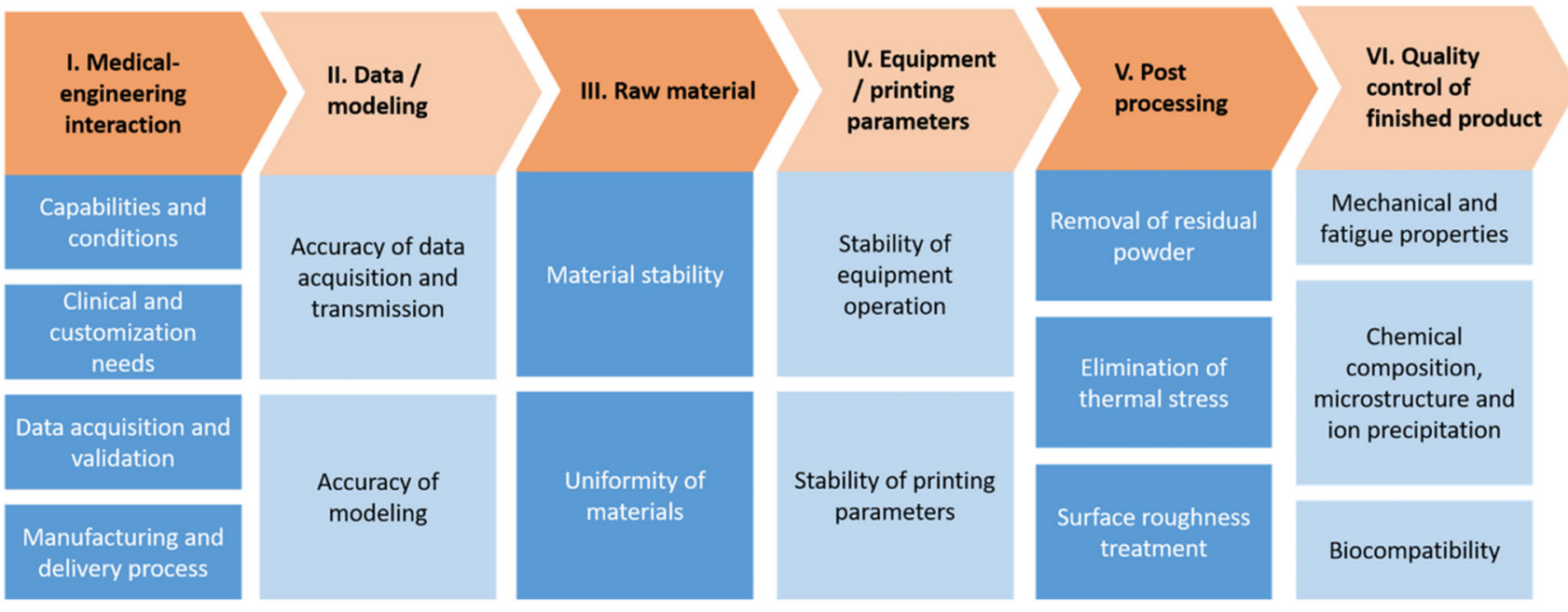

Fig.4 Quality control points of 3D-printed medical devices

fies that the products involved should meet the requirements of six aspects of medical-engineering interaction of additive manufacturing medical devices, including design software, printing equipment, raw materials, printing process verification, post-processing method and verification, and product testing. It is also necessary to confirm the medical-engineering interaction ability from three aspects: personalized design, product delivery, and product application [24]. In conclusion, the concept of medical-engineering interaction is able to connect the key points of quality control.

\section{Raw material quality control}

The quality control of raw materials is the basis of ensuring the quality of printed products. Especially, when it comes to 3D-printed implants or 3D-printed devices used for invasive surgery that have a significant impact on human health, the purity, and performance of the raw materials are especially important [14]. At present, the main raw materials used in additively manufactured medical devices are metal powders for 3D printing, including medical titanium alloys, medical pure tantalum, and medical nickel-titanium alloys.

Different orthopedic implants are typical applications of these powdered metals for 3D printing. Since many bone tissues in the human body have varying porosity, 3D uneven structures from macro- to nanoscale, and differing mechanical strength from the outer to the inner section [20, 53], orthopedic implants not only need to match this functionally graded structure [54], but also feature sufficient toughness, strength, tribology, biocompatibility, and wear resistance between artificial joints [53,55], which often require significant geometric optimization and surface modification [56]. These criteria are challenging to fulfill for the structure and materials of orthopedic implants and make it difficult to realize through traditional manufacturing methods. Titanium alloy and tantalum are well-known for their beneficial mechanical properties, corrosion resistance, and biocompatibility [53, 57]. With the support of 3D printing technology, these powdered metals can well manufacture implants that meet the requirements and are more conducive to osseointegration. Moreover, implant geometry, surface modification, bio-functionalization, and the introduction of vasculature formation are worth considering to realize functional bone regeneration and enhance implant longevity [20]. To achieve optimal results, the first step is to control the quality of these powdered metals. In other words, raw materials for 3D printing are not only raw materials for production, but also the primary objects of risk control for the additive manufacturing of medical devices.

The shape of 3D printing metal raw materials is spherical powder. Therefore, it is essential to characterize these materials in terms of roundness, sphericity, fluidity, compaction density, and loose density, and verify whether their physical and chemical properties meet the requirements of medical device production. Furthermore, because the unique principle of 3D printing allows the recycling of unused powder materials, reused materials may bring additional risks in material properties, such as environmental factors that change the properties of materials or potential material contamination problems. The relevant guidelines of the US FDA have already enlisted some solutions to this problem [40, 47]. Similarly, China's regulatory authorities require manufacturers to describe and verify the mixed powder used for $3 \mathrm{D}$ printing medical devices. For example, the description of powder recovery (recovery time, mixing ratio of new and old powder), the verification of the influence of printing environment on the powder, the demonstration of process stability, and the clinical acceptability need to be disclosed. Through 
these analyses, the potential impacts of powder recycling on the process and results of printing can be judged. Otherwise, the application of recycled powder materials is not allowed [41].

Based on the existing standards, the NIFDC has formulated two basic raw material industry standards according to material type, namely, for medical titanium alloy materials and medical pure tantalum materials. These industry standards are both used as the technical index requirements for manufacturing powder metal raw materials with medical additives, and the specification of raw material requirements in the supplier audit and product review stage.

For medical grade titanium alloy materials, powder composition, morphological characteristics, microstructure, particle size, fluidity, and powder bulk density are the core indexes that should be paid attention to in powder quality control. The standard "Medical Grade Ti-6Al-4 V/Ti-6Al-4 V ELI Powder Used for Additive Manufacturing (YY/T17012020)" was formally implemented on June 1, 2021 in China, which specifies the core contents of the above quality control, and also involves the requirements of roundness or sphericity, material identification, packaging, transportation, and storage.

With regard to medical pure tantalum materials, the standard "Medical Pure Tantalum Powder for Additive Manufacturing" is currently in the pre-project stage, and the key consideration involves two aspects. One is focused on the preparation process of tantalum powder. Because of the high melting point of tantalum, it is difficult to powderize it through the gas atomization process. Spherical tantalum powder is mainly prepared through the radio frequency plasma spheroidization process. The oxygen content is higher during the process of powder preparation. To improve the purity of tantalum powder and control the content of its impurity elements, the oxygen content of non-spherical tantalum powder used for spheroidization needs to be controlled at a low level. Combined with the data of oxygen level increase in the manufacturing process, the oxygen content of tantalum powder is determined to be within $500 \mathrm{ppm}$. The other aspect of the above standard is to pay attention to the SLM molding process. With the increased concentration of particle size distribution of the powder, the internal quality of the printed component of the final molded part becomes improved. Moreover, the particle size of the powder needs to be characterized. This is performed by the common methods of dry sieving and laser particle size diffraction. For $15-53 \mu \mathrm{m}$ powder, the screening method can be adopted to control the proportion of powder above $53 \mu \mathrm{m}$ to be no higher than $10 \%$, so as to ensure that most of the powder is in the particle size range of $15-53 \mu \mathrm{m}$. The particle size distribution requirement of the laser particle size diffraction method is $\mathrm{D} 10 \geq 15 \mu \mathrm{m}, 30 \mu \mathrm{m} \leq \mathrm{D} 50 \leq 40 \mu \mathrm{m}, \mathrm{D} 90 \leq 60 \mu \mathrm{m}$. In addition, the powder fluidity must not be greater than $10 \mathrm{~s} / 50 \mathrm{~g}$, the loose density must be $9.2 \mathrm{~g} / \mathrm{cm}^{3}$, and the vibrated density must be $9.8 \mathrm{~g} / \mathrm{cm}^{3}$.

\section{Management of printing equipment}

Printing equipment consists an essential hardware used for the production of 3D-printed medical devices. The stability of equipment operation and printing process determine whether batch-to-batch differences in the product are within an acceptable range. The printing parameters must have strict verification procedures to ensure the feasibility and stability of the printing process. In addition, when $3 \mathrm{D}$ printing equipment is used for printed medical products, it is often customized, and the rationality and effect of modifications should be verified [52].

\section{Process validation and post-processing management}

The initial product created by 3D printing needs to undergo compulsory post-processing, such as to eliminate thermal stress, surface roughness processing, and remove powder residues. These procedures are important guarantees to ensure the reasonable mechanical properties and biocompatibility of the products. For now, the main problem is that the powder materials used in 3D printing easily remain in the open spaces of the device after printing. The complex structure of 3D-printed devices makes it difficult to perform perfect cleaning and remove these residual powders, which brings risks to product biocompatibility and safety. On the other hand, each enterprise has different cleaning methods that are kept confidential; hence, there is a lack of unified performance requirements and evaluation standards. Therefore, the current process verification standards are mainly aimed at removing the residual powder of 3D-printed products in the post-processing step. At present, the "Validation Method of Cleaning Effect of Metal Powder in Medical Additive Manufacturing Powder-bed Fusion Process" standard formulated by the NIFDC is in the approval stage. Its main purpose is to provide standards for the technical contents of "common cleaning procedures for residual metal powder" and "cleaning effect verification methods." Manufacturers can implement the cleaning process and prove the cleaning compliance according to this standard. The common cleaning methods are mainly high-pressure medium cleaning, ultrasonic cleaning, acoustic dry cleaning, solid medium spraying, and chemical cleaning. The cleaning effect verification methods include appearance inspection, optical inspection, conductivity analysis of final cleaning purified water, $\mathrm{pH}$ analysis of final cleaning purified water, quantitative analysis and characterization of residual metal powder, and industrial computed tomography (CT) inspection. 


\section{Finished product quality control and product application risk assessment}

In addition to meeting the performance requirements after manufacturing, 3D-printed medical devices also need to consider the potential interactions with the human body and subsequent impacts on human health. Implants, for instance, are medical devices that directly interact with the human body, and the metal ion precipitation after implantation needs to be evaluated and controlled. Here, we take 3Dprinted titanium alloy implants as an example to illustrate the current regulatory standards. Such devices use Ti6Al4V powder, in which aluminum $(\mathrm{Al})$ and vanadium $(\mathrm{V})$ are harmful elements. The accumulation of $\mathrm{Al}$ in the body will cause osteomalacia, anemia, neurological disorder, and Alzheimer's disease, while the $\mathrm{V}$ may lead to metabolic disorder, manic depression, and cancer risk. In addition, 3Dprinted implants have high porosity and large specific surface area, thus the risk of metal ion precipitation is higher. With regard to the measurement of metal ion precipitation in 3Dprinted titanium alloy implants, the NIFDC formulated the standard "Methods for the Evaluation of Metal Ion Precipitation in 3D-Printed Titanium Alloy Implants for Additive Manufacturing of Medical Products," which has now been submitted for approval. This standard stipulates that the morphology of the sample used for testing is a porous cylinder with a diameter of $20 \mathrm{~mm}$ and height of $3 \mathrm{~mm}$, prepared according to the product printing process and soaked in Hank's simulated body fluid ( $\mathrm{pH}=7.4$, composed of simulated physiological solution mentioned in Appendix B of the standard YY/T0695-2008 Standard Test Method for corrosion sensitive cyclic potentiodynamic plan of small implant devices). The ion content of the extract is determined by the inductively coupled plasma-mass spectrometry (ICP-MS) method. The metal ions to be detected include Ti, Al, V and the impurity element $\mathrm{Fe}$, as well as other elements, such as $\mathrm{Sn}, \mathrm{Mo}, \mathrm{Cr}, \mathrm{Mn}, \mathrm{Zr}, \mathrm{Ni}, \mathrm{Cu}, \mathrm{Si}, \mathrm{Y}$, etc. (according to the standard GB/C3620.1-2016 for titanium and titanium alloy brand and chemical composition).

Similar to the evaluation of metal ion precipitation, which is a representative product quality and risk control measure, there are other important procedures that are also worthy of attention. The quality of 3D-printed medical device products needs to be controlled from three aspects: physical properties, chemical properties, and biocompatibility. Physical properties should include mechanical properties and fatigue properties; chemical properties are mainly concerned with chemical composition control and microstructure; biocompatibility should be in accordance with the requirements of the GB/T16886 series of standards, based on the contact time and contact parts of the product with the human body, in order to conduct a comprehensive evaluation of the 3D-printed medical device products. In summary, the control of quality and safety risk should be a systematic and complete process, and every detail that may cause harm to human health must be considered.

\section{Performance evaluation and life cycle management}

Just like people that need to walk on two legs, if a robust quality control system is "one leg" to ensure the quality of 3D-printed medical device products, then product performance evaluation and life cycle management consist the "other leg."

In fact, in a broad sense, performance evaluation and full life cycle management are also included in the concept of quality control, but this is because the quality control of additively manufactured medical devices requires more attention and covers a wider range. Therefore, for the convenience of discussion, we divide quality control and performance evaluation into two respective parts. As for the former, we focus more on the manufacturing process, emphasizing that the quality system construction of additive manufacturing can ensure the stable quality of products. Considering the latter, we are more concerned with the performance and application of the product, and its purpose is to ensure product safety and effectiveness through the verification of the personalized product design. These two concerns are precisely the two most critical contents in the "Guidelines for the Technical Review of the Registration of Passive Implantable Bone, Joint and Oral Hard Tissue Personalized Additive Manufacturing Medical Devices (No. 70 of 2019)". Nevertheless, it is important to clarify that quality control and performance evaluation are not independent of each other, and the monitoring and control of safety during the entire process is also an indispensable part of the quality system [58]. Finally, from manufacturing to application, product performance evaluation and full life cycle management are expected to provide additional dimensions for quality and regulation.

In this section, we introduce the details of 3D-printed medical device performance evaluation, pre-market evaluation and post-market follow-up by the regulatory authorities, and point out the importance of life cycle management that is further developed from the entire quality evaluation work.

\section{Performance evaluation}

As mentioned in the previous section, safety is the most important performance measure of medical device products, as well as the first condition for clinical application. To a certain extent, the purpose of evaluating the performance of various aspects of medical devices is safety improvement. To discuss the performance of additively manufactured medical devices, we must first identify the factors that affect safety. 
The safety of 3D-printed medical devices covers a wide range of content. From the point of view of the fabrication process of 3D-printed medical devices, during the initial data collection and modeling stage, the regulatory authorities focused on the safety of product design and software, and the security of data transmission. Ensuring these two aspects is, at the same time, the purpose of the data and software verification work mentioned among the key points of quality control. When a finished product is obtained through the design and manufacturing stage, the factors that will affect the safety of this product include: (1) The safety of the raw materials; (2) The rationality of the structure; (3) The removal effect of processing aids and residues; (4) The biocompatibility of the finished product after implantation into the human body; (5) The long-term toxicity of the product; and (6) The effectiveness of product function.

On the premise of ensuring the above-mentioned safety points, product effectiveness is another factor that needs to be guaranteed the most. Under the requirements of safety and effectiveness, the performance evaluation of 3D-printed medical devices has also yielded several important concerns and regulatory considerations, which mainly include the following four aspects:

The first one is the effective control of processing precision, which can also be referred to as processing accuracy. It requires that the additively manufactured product should be accurate first before its performance can be further evaluated. In the design and manufacturing process of 3D-printed medical devices, the operation of data (i.e., data acquisition method and modeling method), printing process (i.e., the choice of different technologies and the stability of printing parameters), and the quality of raw materials all affect the processing accuracy. In order to ensure that the batchto-batch differences in printing precision and accuracy are within an acceptable range, it is necessary to ensure the stability and reliability of the established data transmission and conversion control method and printing process parameter control method.

The second aspect is to control the mechanical properties of the product. 3D-printed medical device products should meet the mechanical properties required for the intended clinical application. For instance, the product should have static mechanical properties and equivalent fatigue properties that are not lower than those of the forged materials. The orientation and build location in the $3 \mathrm{D}$ printing process can affect the final properties of products [27]. Moreover, the metal 3D printing process will bring some additional adverse effects, such as the physical properties of materials affecting interlayer bonding (a cohesion unique to 3D printing), which should be defined to address concerns of structural integrity [14]. Moreover, the residual thermal stress may cause the deformation and cracking of the printing product structure, or cause microcracks in the material, affecting the perfor- mance of the final product, which can be repaired by hot isostatic pressing. Another problem is that, compared with standard products, it is difficult to select the "worst case" for the performance verification of personalized products, and it is also unrealistic to verify each design. As per the "Guidelines for the Technical Review of the Registration of Passive Implantable Bone, Joint and Oral Hard Tissue Personalized Additive Manufacturing Medical Devices (No. 70 of 2019)" and the "Guidelines for the Technical Review of the Registration of Equivalence Models of Customized Personalized Bone Implants" [46], equivalent models should be used for mechanical performance and structural verification tests. An equivalent model is "a digital and physical model that maximizes the simulation product and the biomechanical environment in which it is located" [32], and one that provides a new means of testing on the basis of the traditional performance evaluation method.

The third aspect is to control the biocompatibility of products. Biocompatibility is a key factor for 3D-printed medical device products to allow for a clinical therapeutic effect. To ensure biocompatibility, the quality of powder raw materials should be guaranteed first. On the other hand, from the perspective of performance evaluation and improvement, the interconnected porous structure of 3D-printed medical devices can provide a suitable 3D environment for cell growth and ensure the necessary spaces for the generation of blood vessels and nervous system. Therefore, it can elevate the strength of tissue material fusion interface and promote the formation of bone tissue in a 3D structure. In view of these functions, the biocompatibility of the printed structural parts can be further enhanced by acid-base post-processing or bioceramic coating. An appropriate process must be applied to remove the powder residue after printing. Finally, a comprehensive biocompatibility evaluation of 3D-printed medical device products should be carried out in accordance with the requirements of the GB/T16886 series of standards.

The fourth aspect is to assess the clinical applicability of the product. 3D-printed medical devices ultimately need to meet the individual needs of patients. Although the devices themselves are products printed according to the patient's individual characteristics and the 3D data obtained by clinical diagnostic techniques, such as CT, whether they can achieve the expected effect still needs to be verified. At the quality control level, it is essential to ensure a good medical-engineering interaction throughout the entire process. In terms of performance evaluation, carrying out preclinical animal experiments, establishing non-destructive performance evaluation projects, setting up digital methods to simulate product functions, and collecting data on the effects of implants after implantation in the human body for product improvement are all feasible means to ensure the clinical applicability of products [50]. 
Table 4 Criteria of pre-market quality evaluation (taking 3D-printed titanium alloy orthopedic implants as an example)

\begin{tabular}{|c|c|c|}
\hline & Evaluation points & Evaluation criteria \\
\hline 1 & Quality control of raw materials & $\begin{array}{l}\text { According to the requirements of "YY/T1701-2020 Medical Grade } \\
\text { Ti-6Al-4 V/Ti-6Al-4 V ELI Powder Used for Additive } \\
\text { Manufacturing", including powder chemical composition, } \\
\text { particle size, particle size distribution, sphericity, loose density, } \\
\text { tap density, fluidity, etc., the recyclable times of powder, } \\
\text { screening method, mixing ratio of new and old powder (if } \\
\text { appropriate), etc. shall be specified, and the verification data of } \\
\text { the impact of powder recovery on the printing process and related } \\
\text { product performance shall be provided }\end{array}$ \\
\hline 2 & On the minimum structural element of porous part & $\begin{array}{l}\text { Provide the selection and setting basis of the minimum structural } \\
\text { unit for product printing, such as the quality control range and } \\
\text { determination basis of pore unit shape, pore size and its } \\
\text { distribution, wire diameter, porosity, average pore intercept, pore } \\
\text { gradient, internal connectivity, thickness of porous structure, etc }\end{array}$ \\
\hline 3 & Unique risks posed by porous structures & Measurement of hemolysis and metal ion precipitation \\
\hline 4 & Verification of processes with special risks & Validation of cleaning process for printing powder residue \\
\hline 5 & Physical and chemical properties & $\begin{array}{l}\text { Chemical composition, microstructure and corrosion resistance of } \\
\text { the final product }\end{array}$ \\
\hline 6 & Defect control & $\begin{array}{l}\text { Use appropriate means to monitor the defects of the internal } \\
\text { structure, such as wire diameter breaks, closed holes, etc., and } \\
\text { formulate an acceptable basis }\end{array}$ \\
\hline 7 & Mechanical properties & $\begin{array}{l}\text { The selection of the worst case should be combined with } \\
\text { biomechanical analysis such as product material property test, } \\
\text { product design characteristics and finite element simulation. The } \\
\text { mechanical properties of porous structure and solid structure can } \\
\text { be studied by the same process sample block or test bar, } \\
\text { respectively. Inspect the tensile, compression, bending, shear, } \\
\text { impact, hardness and fatigue properties of products }\end{array}$ \\
\hline 8 & Biosafety and biocompatibility & $\begin{array}{l}\text { Sterility and endotoxin limit, cytotoxicity, sensitization, irritation, } \\
\text { systemic acute toxicity, subchronic toxicity, genotoxicity, } \\
\text { implantation experiment, blood compatibility }\end{array}$ \\
\hline 9 & Sterilization, packaging and transportation & $\begin{array}{l}\text { According to the "YY/T 0640-2016 Non-active surgical } \\
\text { implants-general requirements", including confirmation of the } \\
\text { sterilization process, verification that the sterilization method } \\
\text { does not affect implant safety or performance, and sterilization } \\
\text { residue test; validation of packaging methods. The packaging } \\
\text { should protect the implant from damage during storage and } \\
\text { transportation and maintain its sterility level. The manufacturer } \\
\text { shall specify the method of storage and transportation }\end{array}$ \\
\hline 10 & Preclinical effectiveness in large animals & $\begin{array}{l}\text { Carry out large animal experiments that simulate clinical use (such } \\
\text { as implantation after bone defect) for more than half a year. The } \\
\text { analyses that need to be carried out include image analysis, } \\
\text { mechanical analysis, and pathological analysis. The safety } \\
\text { indicators include biochemistry, hematology, etc }\end{array}$ \\
\hline
\end{tabular}

\section{Pre-marketing quality evaluation and post-marketing follow-up}

Through the quality control of the design and manufacturing process and the performance evaluation of finished products, 3D-printed medical device products that meet the standard requirements come very close to the goal of introduction to the market, but there is the important preceding step of premarket quality evaluation. Take the pre-market evaluation of 3D-printed titanium alloy orthopedic implants as an exam- ple. At present, the regulatory authorities mainly focus on 10 relevant evaluation points, which comprehensively cover the materials, structure, process, performance, and other aspects. These points and their specific evaluation criteria are summarized in Table 4.

The step of obtaining regulatory approval and listing is far from completing the supervision of 3D-printed medical devices. On the contrary, clinical application after marketing is the true test of the effectiveness of such devices. Postmarketing follow-up is as important as pre-marketing quality 
evaluation. The former is not only a follow-up of the effect of the 3D-printed medical device after implantation in the human body, but also, if there is an adverse event and the implant needs to be removed, it is necessary to establish the removal operation process and the technology of product testing and analysis after removal to find out the cause of product failure. Last but not least, 3D-printed medical devices should have unique identification numbers, and the production records and sales records should be archived to ensure traceability from raw materials to production processes, postprocessing procedures, and to sales.

\section{Full life cycle management}

From the quality control of design and manufacture to the quality evaluation, pre-market evaluation, and post-market follow-up of the finished product, the topic of regulation and standardization of additive manufacturing medical devices continues. It is encouraging that in recent years, people have quickly accumulated a great pool of experience in the exploration of standardizing 3D-printed medical devices. All links of quality control and performance evaluation are gradually being improved, and the relevant regulatory regulations and guidance are also being gradually introduced. Although these regulatory elements with a wide range of content and coverage may seem confusing at first, in fact, all links are interconnected. The ultimate goal is the life cycle management of additive manufacturing medical devices, which means connecting them in series (Fig. 5).

Since the various links are to be connected in series, the regulatory authorities will first take measures and formulate corresponding procedures to ensure the reasonable connection of the entire process of diagnosis, manufacturing, treatment, and regular observation after implantation. In the diagnosis and design process, the concept of medical-engineering interaction and its importance is introduced into the quality control system. In the manufacturing process, through quality control and establishing procedures, the following tasks are performed to ensure the traceability of the production process and stability of product batches: professional production personnel management, equipment management, raw material control, process verification, environmental control, adverse event monitoring analysis and improvement. In the application phase, follow-up is made robust through data collection, recording and analysis as the core, and the follow-up results are used to improve the product design, and finally the application phase is linked to the design phase to achieve a closed loop of full life cycle management.

Just like the key to medical-engineering interaction is the cooperation of personnel with multi-disciplinary and multiprofessional backgrounds, which runs through the whole quality control process, the entire process of life cycle man-

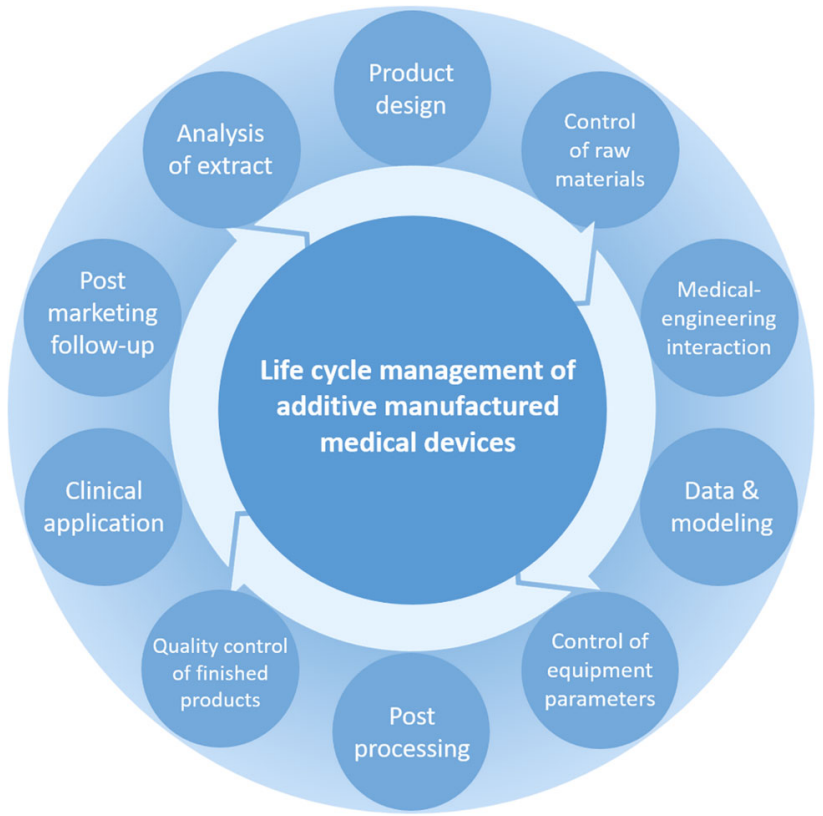

Fig. 5 Life cycle management of 3D-printed medical devices

agement is not only the responsibility of the regulatory department, nor the task that can be completed by one party, but it also relies on the cooperation of the government, manufacturers, suppliers, and research institutions [59]. Especially in the face of the emerging field of additive manufacturing of medical devices, even in the case of laws and regulations, there are bound to be certain details that are difficult to cover. More often than not, regulations are to provide a framework for medical device companies $[14,48]$. In addition to creating products that meet the required standards, it is also important for companies to substantively consider and play a role in the concept of full product life cycle [14]. In general, compared with conventional medical devices, the system and product standard construction of additively manufactured medical devices require more human resources and energy [59]. Nonetheless, the advantages of additively manufactured medical devices are unparalleled. The large investment in early exploration is worthwhile in exchange for improving the effect of disease treatment and protecting human health.

\section{Discussion}

In the above sections, we reviewed the progress of China's standardization of 3D-printed medical devices and summarized the current focus of regulation and standardization of such devices. As the subject of this review, the concept of "Standardization of Additive Manufacturing Medical Devices," as the name suggests, can be divided into three keywords. "Additive manufacturing" is the method of manufacturing products, "medical devices" are products, and 
"standardization" is the process to make products meet certain requirements. Obviously, products that do not meet these requirements cannot be used in clinical applications, and therefore cannot be justified. "Standardization" provides the most significant application guarantee for innovative products such as 3D-printed medical devices, and its importance and necessity in connection with the products are self-evident. The advancement of standardization can also promote the development of the entire 3D printing and medical device industry. The establishment of standards can form a basis for the industry's research, development and production activities, as well as the review and approval work of the regulatory authorities, and it can also provide a broader platform for inter-industry exchanges and multidisciplinary cooperation [52].

Systematicity and extensiveness are the characteristics of standardization work, which have been reflected in the concepts of quality control, performance evaluation, and full life cycle management, as reviewed in the previous section. When familiarity with standardization work is lacking, it is often difficult to realize its importance, or people may believe that standardization is just a number of regulations promulgated by the regulatory authorities, thus classifying systemic work as a unilateral task. With the rapid development of 3D-printed medical device standardization in recent years, the one-sided understanding of standardization has been gradually improved. The importance and necessity of standardization are accepted by a growing number of people within and outside the field, thus forming a more favorable environment for the promotion of standardization work.

At present, based on the characteristics of the standardization process, in order to continue to promote the standardization of 3D-printed medical devices, it is essential to simultaneously promote many aspects of work [52], including: (1) Enhance the industrialization process of China's additive manufacturing technology; (2) Strengthen the exchanges and cooperation in standardization work between China and other countries and organizations; (3) All parties in the field should provide constructive opinions for the establishment of relevant laws and regulations by the Chinese regulatory authorities; (4) All parties in the field should provide technical support for formulating regulatory guidelines, such as special risk analysis and risk control; (5) The regulatory authorities shall further establish standards for technologies and methods, raw materials, equipment, and processes. It can be seen that, firstly, industry and standards are interdependent, and industry cannot be separated from the guidance of standards, nor can standards be separated from industry; otherwise, they become "castles in the air." Secondly, the additive manufacturing of medical devices is a topic of global concern. Although this review focuses on the development of standardization work in China, it does not mean that this is done behind closed doors; it is highly important to learn from similar efforts in the world, as different countries and institutions can complement each other. Finally, industry, education, scientific research, inspection agencies, medical units, standardization agencies, and regulatory agencies are all important players in this field. According to the different divisions of labor, all parties realize synergy and integration in terms of function and resource advantages, and jointly promote the development of additively manufactured medical device standardization.

The coordinated advancement of many aspects of work has broadened people's vision of the standardization of additively manufactured medical devices. Similarly, a broad vision is equally important for the concepts within standardization work. Taking generalized quality control as an example, although the previous sections have summarized various points of concern in terms of quality and performance, they are far from the whole process of quality control. Broad vision means not only paying attention to the details in each link, but also considering the overall situation on a larger scale to form a unified perspective and stand in a higher dimension. In the activity of "2020 Medical Device Safety Promotion Week," NIFDC showed the "Eight dimensions of quality control" formed by the latest components of the evaluation of additively manufactured medical devices [60], including performance, features, reliability, consistency, durability, operational performance, aesthetics, and perceived quality. On a higher level, these eight dimensions are divided into three quality methods: product-based approach, manufacturing-based approach, and user-based approach, which relatively comprehensively and systematically ensure the quality of 3D-printed medical devices and at the same time, meet the needs of users. These eight dimensions, combined with industry needs, together constitute the entry points for standardization work, which are also applicable to companies that are new to or wish to enter this field, as it can help these companies better understand the seemingly complex standardization work from scratch. The meaning of the old saying in China, "cope with shifting events by sticking to a fundamental principle," is reflected in the standardization work; that is, although the products are personalized, the workflow and operation methods can still be standardized. Standardization processes are used to standardize various personalized products [32], which means to meet all changes with constancy. Understanding these principles, coupled with constant familiarity with regulations and 3D printing technology, companies can better innovate their products according to standards, truly use new technologies to develop new products, and at the same time meet approval requirements.

Considering the product itself, two main problems remain for additively manufactured medical device products: (1) The means to use a unified standard to evaluate personalized products; (2) In research and development, how to achieve a balance between innovation, safety and effectiveness [13]. 
Some evaluation methods for personalized products have been reflected in the existing regulatory regulations and guiding principles. To offset the differences between personalized products and traditional products, the "Trinity" evaluation path has been established, which involves direct product performance evaluation, the control of the whole process of design and manufacturing, and the indirect verification of product performance by using an "equivalent model" similar to products. Regardless of the method used, it should meet the requirements of fast evaluation speed and high accuracy; otherwise, it will weaken the benefits of additive manufacturing personalized products [50]. Although such products are personalized, their direct performance evaluation is still necessary. Through some non-destructive test projects, the mechanical properties and structural accuracy of the products can be evaluated. Combined with doctors' rich clinical experience and cognition of the product, its comprehensive evaluation can better ensure its safety and effectiveness [61]. In this regard, the entire process control of design and manufacturing and the testing of "equivalent model" are all indirect methods.

In addition to the quality control points that have been reviewed, from the perspective of "input-output process," according to the "YY/T0287-2017 Medical Devices-Quality Management Systems-Requirement for Regulatory Purposes" standard, a complete design and development process should start from the design input (clinical requirements) and go through the verification and confirmation process of design and development, and complete with the design output (product design). During the review, attention shall be paid to the adequacy and integrity of the design verification and validation process [32]. Compared with standardized products, personalized products add consideration to the needs of specific patients during input, and the verification of the process from input to output changes accordingly. Nevertheless, the core idea is the same: if we ensure that each input and the process from input to output meet the requirements, we can indirectly prove that the output meets the requirements.

Regarding the balance between innovation, safety, and effectiveness, this can be actually divided into two topics for discussion, namely, the relationship between the pursuit of innovation, and the pursuit of safety or effectiveness. Since it is meaningless to directly compare the importance of safety and effectiveness, we can try to clarify the goals that 3D-printed medical device products should pursue from two contexts. Firstly, with regard to the balance between innovation and safety, "balance" here does not mean that these are equally important, but it emphasizes that safety should not be neglected during the blind pursuit of innovation. The safety of additively manufactured medical devices is much more important than innovation not only because medical devices are directly related to human health, but also because of their simple and clear purpose, which is to aid clinical treatment.
These products only need to meet the needs of patients without any additional "fancy" appearance or "cool" functions. On the premise of meeting patient needs and safety, more innovative designs can be incorporated when improving the product, but the purpose of making the product more effective should remain. Secondly, regarding the balance between innovation and effectiveness, the latter should also be the goal. Effectiveness here is not limited to the requirements for products already manufactured in the existing industry, but can also be extended to the requirements for 3D-printed medical devices used in scientific research, even if they are still in the laboratory. In the study of 3D-printed medical device products, establishing the awareness of industrialization and clinical transformation should be a significant principle throughout the research and development process.

In other words, it should be the ultimate goal of any research on medical devices to promote their role in clinical applications. This is equivalent to scientific research institutions and laboratories devoting themselves to transforming the scientific research results of 3D-printed medical devices into products that can enter clinical applications, instead of leaving them in the scientific research stage just for the sake of publishing papers. Similarly, when moving from the scientific research stage to the industrial stage, the requirement for medical device companies is that when a 3D-printed medical device product is developed, it cannot be only for the aim of approval and certification by the regulatory authorities. Product certification is only the beginning step of product application, whose effectiveness should be the ultimate pursuit of medical device products.

\section{Future perspectives}

Similar to the continuous innovation during the research and development of 3D-printed medical devices, the standardization of such devices in China in recent years has been constantly taking the essence of the traditional basic technology risk control evaluation system to remove unsatisfactory items, and innovating a new regulatory system that matches new technologies and products. Based on the work done so far, it can be seen that "quality" and "risk" remain the two keywords in connection with the exploration of 3D-printed medical device regulation. More quality control points are being discovered, and further potential product risk factors are being precisely controlled. Although the existing work is overall still in its infancy, such as the standards for raw materials cover only a few metal materials, and the process standards mainly involve the cleaning stage in the posttreatment process, it is important that these efforts have made China take a huge step from no activity to being a true player in the regulation of 3D-printed medical devices. The country has also clarified the focus of regulation and standardization 


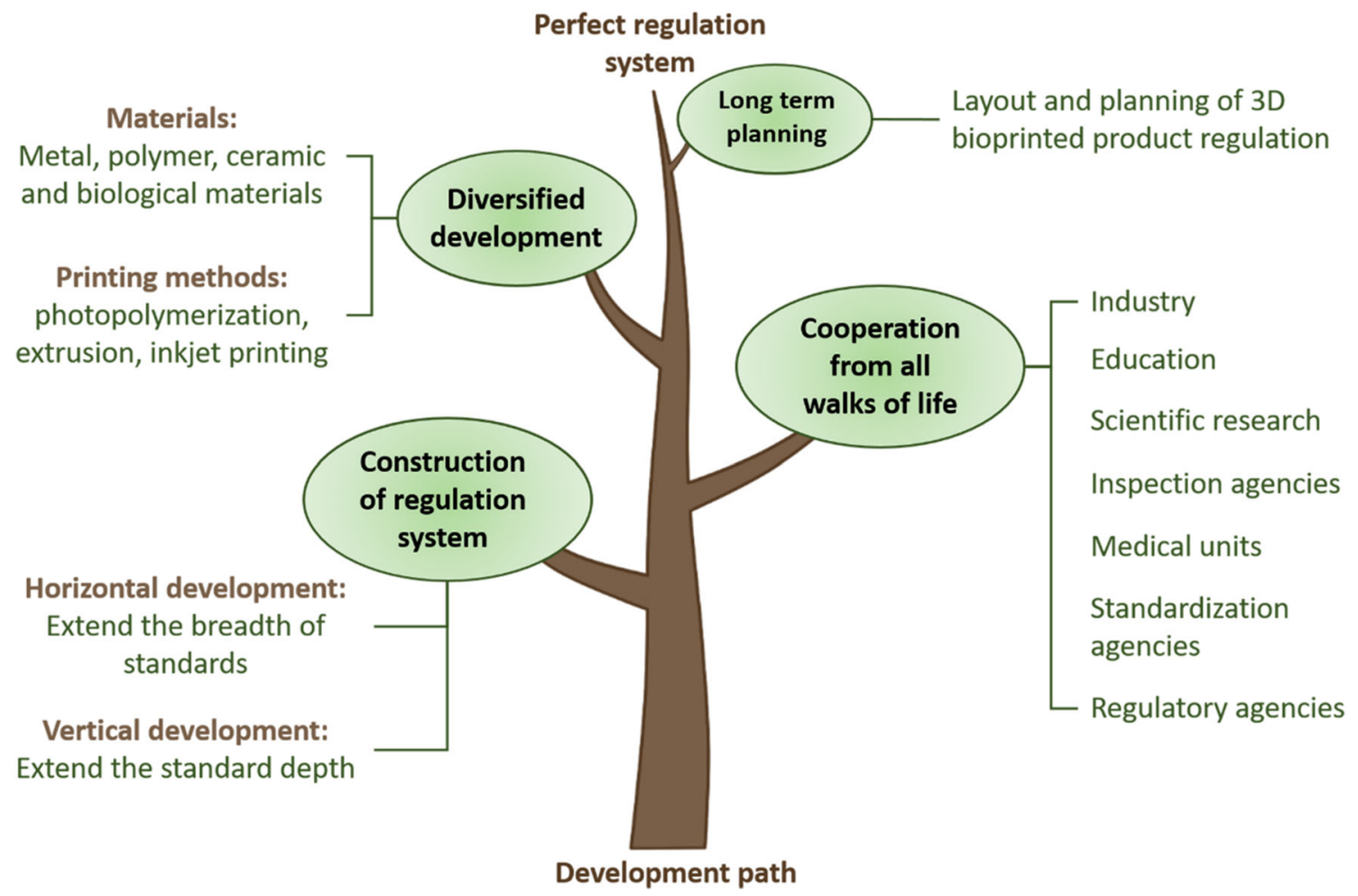

Fig. 6 Future development of the regulation and standardization of 3D-printed medical devices

work, laying the path for longer-term development in the future. It is expected that medical device regulation will continue to evolve and embrace more unknowns and challenges (Fig. 6) [27].

In the future development of standardizing additively manufactured medical devices, the highest priority is still given to the construction of guiding principles, standards, and regulatory systems. It is important to note that standardization and regulation are not arbitrary. The basis for ensuring the rationality and effectiveness of work is strictly carrying out relevant work in accordance with the corresponding regulations, such that supervision, research, and production can be followed. The construction of a 3D-printed medical device standardization and regulation system has been listed as one of the important tasks in China's 14th Five-Year Plan. In general, the construction direction can be divided into a horizontal and a vertical element. The horizontal one is to expand the breadth on a large scale, so that the standard covers more types of technology and product, and the vertical one is to extend the depth of the standard to cover more details for specific products and technologies.

From the perspective of 3D printing technology and materials, since metal implants are one of the most widely used 3D-printed medical devices, many existing standards are also aimed at the technologies and powdered metals involved in metal 3D printing, which also causes certain limitations. More types of material, such as photocurable resins or polyamide materials could be used for dental applications, as surgical support structures, or surgical cutting guides [16]. The unique properties of these materials, which are different from metals, can enable 3D-printed medical devices to achieve more functions. To realize the regulation of more material types, the horizontal construction of standards needs to be carried out. The challenges brought by the application of these new materials for regulation are not only the increased number of material types, but also the changes of material state (e.g., powder, filamentous, solid or liquid), changes of the $3 \mathrm{D}$ printing process as required by materials (e.g., vat photopolymerization, material extrusion and inkjet printing), as well as the different application scopes and performance requirements of medical devices made from different materials. Therefore, any horizontal expansion of standardization means establishing a larger framework for the system.

In contrast, the vertical construction of the system is to continuously improve the details of the large framework formed by horizontal development. Based on precise risk control, in view of the characteristics of strong innovation, weak industrial foundation and high demand for standards in the relevant industry, the NIFDC is carrying out a further standardization work layout, forming a series of future research plans and improvement directions, involving multiple details in the general requirements for process validation, quality control methods, data and software requirements, and performance test methods, as shown in Table 5. Besides, in 
Table 5 Pre-research standards based on precise risk control

\begin{tabular}{|c|c|c|}
\hline Standard category & Involved content & $\begin{array}{l}\text { Planned } \\
\text { improvement } \\
\text { direction }\end{array}$ \\
\hline $\begin{array}{l}\text { General } \\
\text { requirements for } \\
\text { process } \\
\text { verification }\end{array}$ & $\begin{array}{l}\text { Special } \\
\text { requirements for } \\
\text { the process } \\
\text { verification of } \\
\text { SLM and EBM } \\
\text { (electronic beam } \\
\text { melting) for metal } \\
\text { additive } \\
\text { manufacturing }\end{array}$ & $\begin{array}{l}\text { Investigate the } \\
\text { production } \\
\text { process to make } \\
\text { the standard more } \\
\text { in line with the } \\
\text { actual situation of } \\
\text { the industry }\end{array}$ \\
\hline \multirow[t]{2}{*}{$\begin{array}{l}\text { Quality control } \\
\text { methods }\end{array}$} & $\begin{array}{l}\text { Evaluation method } \\
\text { for the rationality } \\
\text { of the bionic } \\
\text { structure of } \\
\text { 3D-printed } \\
\text { orthopedic } \\
\text { external fixation } \\
\text { devices }\end{array}$ & $\begin{array}{l}\text { Research and verify } \\
\text { specific test } \\
\text { methods for } \\
\text { evaluation }\end{array}$ \\
\hline & $\begin{array}{l}\text { Industrial CT } \\
\text { inspection of } \\
\text { additively } \\
\text { manufactured } \\
\text { metal implants }\end{array}$ & $\begin{array}{l}\text { Clarify the } \\
\text { parameter setting } \\
\text { requirements } \\
\text { according to the } \\
\text { characteristics of } \\
\text { additive } \\
\text { manufacturing }\end{array}$ \\
\hline $\begin{array}{l}\text { General } \\
\text { requirements for } \\
\text { data software }\end{array}$ & $\begin{array}{l}\text { Basic requirements } \\
\text { for the } \\
\text { construction of } \\
\text { 3D-printed } \\
\text { medical-industrial } \\
\text { interactive } \\
\text { platform }\end{array}$ & $\begin{array}{l}\text { Focus on the data } \\
\text { processing } \\
\text { requirements of } \\
\text { enterprises }\end{array}$ \\
\hline $\begin{array}{l}\text { Performance } \\
\text { evaluation method }\end{array}$ & $\begin{array}{l}\text { Test method for the } \\
\text { mechanical } \\
\text { properties of } \\
\text { additively } \\
\text { manufactured } \\
\text { polyether ether } \\
\text { ketone }\end{array}$ & - \\
\hline
\end{tabular}

some other aspects, the planned research direction of 3Dprinted medical device standardization during China's 14th Five-Year Plan period also includes the content enlisted in Table 6. The construction of these standards and regulations is not only used to standardize the products themselves, but also to promote a reasonable connection from diagnosis to manufacturing to treatment. In future development, sound laws and regulations will further establish the links of whole product life cycle and the whole process of medical-industrial interaction, and provide a full range of guarantees for the development of 3D-printed medical devices.

Furthermore, the cooperation of multiple disciplines and institutions will jointly promote the development of standardization of 3D-printed medical devices. Standardization work in this field must be the result of the joint efforts of all
Table 6 Other research directions of standardization work during the 14th Five-Year Plan

\begin{tabular}{ll}
\hline Standard & Research directions \\
\hline Raw material standards & Technical considerations for \\
& material reuse requirement \\
& standards \\
Process verification method & methods for the stability of \\
standards & processing and verification \\
methods for the stability and & effectiveness of the \\
post-treatment process, such & as verification method \\
standards for the powder \\
removal process \\
Dedicated mechanical \\
performance testing methods: \\
mechanical and fatigue \\
performance testing methods, \\
and non-destructive testing \\
methods \\
Chemical characteristics testing \\
method: crystal structure and \\
composition test method \\
Special biological risk \\
evaluation methods: \\
evaluation methods for the \\
rationality of bionic structures \\
and evaluation methods for \\
the toxicological effects of \\
particles \\
Establish requirements for \\
different molding processes, \\
method \\
such as extrusion, direct \\
energy deposition, laser \\
melting, etc. Establish both \\
general requirements and \\
specific requirements for \\
printing equipment dedicated \\
to additive manufacturing of \\
medical devices \\
\\
\end{tabular}

parties involved. For 3D-printed medical devices, the field formed by the intersection of medicine, engineering, and many other disciplines more clearly reflects the importance of multidisciplinary and multi-institutional cooperation, which even includes the contributions of sectors of society outside the field. Communication between regulators and the public is always essential [16]. While NIFDC carries out standardization research, it also continues to solicit standardization research project proposals from the whole society. Subsequently, NIFDC will evaluate the proposals and send the feasible ones to the NMPA for defense and expert discussion. 


\begin{tabular}{|c|c|c|}
\hline Steps & Content & Ways for all sectors of society to participate \\
\hline \multirow{2}{*}{1} & \multirow{2}{*}{$\begin{array}{l}\text { a) Project pre establishment } \\
\text { b) Project establishment }\end{array}$} & $\begin{array}{l}\text { a) The standard project proposal can be put forward in the } \\
\text { standard management center throughout the year }\end{array}$ \\
\hline & & $\begin{array}{l}\text { b) Opinions and suggestions can be put forward during } \\
\text { the publicity of project initiation }\end{array}$ \\
\hline \multirow{2}{*}{2} & \multirow{2}{*}{$\begin{array}{l}\text { a) Drafting } \\
\text { b) Solicitation of opinions }\end{array}$} & $\begin{array}{l}\text { a) It can be applied as a standard drafting unit or } \\
\text { verification unit }\end{array}$ \\
\hline & & b) Feedback and suggestions in public or in writing \\
\hline \multirow[b]{2}{*}{3} & \multirow[b]{2}{*}{$\begin{array}{l}\text { a) Technical review } \\
\text { b) Review and issue }\end{array}$} & $\begin{array}{l}\text { a) Consult the information of the standard review meeting } \\
\text { published by the standard management center }\end{array}$ \\
\hline & & $\begin{array}{l}\text { b) Consult the published standard catalogue, text and } \\
\text { annual report information }\end{array}$ \\
\hline \multirow[b]{2}{*}{4} & \multirow{2}{*}{$\begin{array}{l}\text { a) Propaganda and training } \\
\text { b) Re-examine and } \\
\text { implementation evaluation }\end{array}$} & $\begin{array}{l}\text { a) Participate in the training according to the open } \\
\text { training plan and notice }\end{array}$ \\
\hline & & $\begin{array}{l}\text { b) Feedback suggestions on the public communication } \\
\text { platform and implementation process }\end{array}$ \\
\hline
\end{tabular}

Fig. 7 Participation in the whole process of medical device standard formulation

This shows that all sectors of society can play an important role in the formulation of standards in this field (Fig. 7).

With regard to multi-institutional cooperation, given the lack of experience in the application of 3D printing in the medical field, research institutions should strengthen the research on printing technology and principles, and develop more suitable printing materials, higher precision equipment, and modeling software with independent intellectual property rights. Medical device manufacturers should do a satisfactory job in production management to improve printing precision and controllability. The testing institutions are responsible for the quality evaluation of 3D-printed medical devices, and they need to strengthen the research on testing methods and process verification methods. Standardization research institutions should improve the overall standardization research of 3D printing. National regulatory agencies should also closely track changes in the production technologies and industries, formulate appropriate regulatory regulations, and standardize industrial development. Moreover, another aspect that may be easily overlooked is the cultivation and education of talents [62]. 3D-printed medical equipment and its standardization research are an emerging field, and traditional professional education can hardly keep up with the demand for professional knowledge in this area. In the current situation of the shortage of 3D printing technical talents and medical workers as interactive talents, it is essential for colleges and vocational schools to set up relevant majors to cultivate more workers and research talents who can be competent in the new production mode. Large manufacturing or technology companies could invest equipment resources in schools to further make up for the lack of additive manufacturing education. The cross-training of existing talents is another feasible strategy. For instance, design engineering training for some doctors, or anatomy and surgical procedure training for some biomedical engineers could be organized, so that they could act as coordinators of the development workflow of 3D-printed medical products [63]. As for the government, more policies should be promulgated to ensure the training, employment and skill improvement of relevant talents, and bring the attention of all sectors of society to the development of this field.

Finally, the regulatory authorities shall focus on the longer term to make the regulatory and standardization work cover more levels of the application of 3D printing in medical treatment. The use of general 3D printing technology to manufacture medical devices that contain no cells and biologically active substances comprises only the two lowest levels of 3D printing in medical applications. Any additional level of clinical application of 3D-printed medical products depends on the simultaneous progress of standardization work and 3D printing technology. On the one hand, with the establishment of a standard system urgently needed by 
the current 3D-printed medical device industry, the standardization of these devices will enter a mature stage from the preliminary exploration stage, and people will accumulate a lot of experience in this process. On the other hand, with the continuous development of 3D printing technology and materials, the number of technologies that can be maturely applied in the industry will also increase. The 3D printing technology that contains cells and biologically active substances, called 3D bioprinting [64-67], has gradually stepped into the stage of medical product manufacturing. However, it has to be acknowledged that the introduction of biological ingredients into products necessitates extensive technical considerations in manufacturing and regulation $[68,69]$, and is accompanied by great challenges. Although in terms of technology, the scientific community has carried out extensive research on 3D bioprinting, there are still very few 3D bioprinting products that can be actually applied in clinics, only showing some potential application prospects [70-72].

Therefore, for the transformation from 3D-printed medical devices to 3D bioprinted products, it may be more feasible to adopt multi-stage gradual development rather than hoping to realize the application and regulation of complete biological 3D printing products in a single step. One path that can be considered is to temporarily treat biological 3D-printed medical products as a combined product of multiple concepts [73], first evaluate and supervise each subdivision concept, and finally attempt combined application. For instance, as an implant, a scaffold with cells can be divided into the concept of cell therapy or biologics, and a 3D-printed scaffold without cells; there are existing laws and regulations for the supervision of these two concepts. After they have been proved to be feasible and approved, their combined concept, that is, the implanted stent with cells, can be endeavored to be evaluated. Particularly, the unique factors in 3D bioprinting require additional attention, such as in applications where the cell supply is limited and labile, and high-order cell function must be retained [62, 74]. Furthermore, the regulatory authority can re-clarify the regulatory requirements based on the evaluation results, first improve the regulations of the two concepts, and then formulate new regulations specifically for 3D-bioprinted medical products based on the accumulated experience. Through such an indirect evaluation path, a direct supervision system for 3D-bioprinted medical products can be established, and biological 3D printing products can be divided into special regulation categories. Although there have been questions on the necessity of setting special categories [75], we believe that a clear classification of different types of medical products is more conducive to management, to clarifying the responsibility boundary [62], and to the general understanding of the regulation of medical products.

With the above feasible approaches, we also wish to share some of our predictions and views on the time perspective of the future development of 3D-printed medical product regulation and standardization. China's standardization work has achieved rapid development in the recent three years. Based on the 14th Five-Year Plan launched in 2021, we expect that China will establish a basically perfect regulation and standardization system for general 3D-printed medical devices without cells by 2025 , covering most personalized medical devices that are in clinical need. Meanwhile, in the next three years, regulatory authorities should pre-layout the regulatory research on 3D-bioprinted medical products, and explore more feasible application paths for these special products. After 2025, it may be possible to formally carry out regulatory research on biological 3D-printed medical products. The intermediate development stage of each feasible path is expected to last for 5-10 years, which will also depend on the actual progress of 3D bioprinting. Then, by 2035 , a basically complete and systematic regulation system for biological 3D printing products will be established, the application level of 3D printing in medical treatment will be further improved, market-oriented products will be more abundant, and different levels will have space to flourish. In general, under the guidance of regulation and standardization work, the vigorous development of 3D printing for medical applications is an inevitable trend, but there is still a long way to go. The efforts of the regulatory authorities will not end with the establishment of laws and regulations, and the same is true for scientific research institutions, manufacturing companies, universities, and various other parties associated with this field.

\section{Conclusions}

In summary, as a new technology introduced to the medical field, additive manufacturing has brought a new revolution to the research and development of medical devices, but it also has a series of additional risks. The regulation and standardization of 3D-printed medical devices comprise the work necessary to control these risks and make the performance of these products meet the application requirements. In this review, we have summarized the advancements and specific research focus of China's 3D-printed medical device regulation and standardization activities and emphasized the key aspects of quality control, risk control, performance evaluation, and full life cycle management. The lack of current regulation work and the urgent need for improvement were also discussed, combined with some predictions about the timing of future development. We anticipate that this review could provide recommendations for regulatory authorities, and more importantly, point out the significance of regulation to the entire industry, along with helping companies that may wish to enter this field to better understand the current regulatory system to produce qualified products. With the 
continuous development of 3D printing technology, materials and standardization work, more types of 3D-printed medical products are expected to change people's life quality in the future.

Acknowledgements This work was sponsored by the National Natural Science Foundation of China (No. 81827804, U1909218) and the Science Fund for Creative Research Groups of the National Natural Science Foundation of China (No. T2121004).

Author contributions ZBYJ involved in conceptualization, investigation, visualization, writing (original draft, review and editing); $\mathrm{CFH}$ involved in visualization; JZF involved in conceptualization; QQH involved in conceptualization, resources, and writing (review and editing); YH involved in conceptualization, funding acquisition, and writing (review and editing).

\section{Declarations}

Conflict of interest The authors declare that there is no conflict of interest.

Ethical approval This study does not contain any studies with human or animal subjects performed by any of the authors.

\section{References}

1. Pane J, Francisca RDC, Verhamme KMC et al (2019) EU postmarket surveillance plans for medical devices. Pharmacoepidemiol Drug Saf 28(9):1155-1165. https://doi.org/10.1002/pds.4859

2. Levy GN, Schindel R, Kruth JP (2003) Rapid manufacturing and rapid tooling with layer manufacturing (LM) technologies, state of the art and future perspectives. CIRP Ann 52(2):589-609. https:// doi.org/10.1016/s0007-8506(07)60206-6

3. ISO, ASTM International. ISO/ASTM 52900: Additive manufacturing-general principles-terminology. 2015

4. Liaw CY, Guvendiren M (2017) Current and emerging applications of 3D printing in medicine. Biofabrication 9(2):024102. https://doi. org/10.1088/1758-5090/aa7279

5. Parihar A, Pandita V, Kumar A et al (2021) 3D printing: advancement in biogenerative engineering to combat shortage of organs and bioapplicable materials. Regener Eng Transl Med (Online). https://doi.org/10.1007/s40883-021-00219-w

6. Matai I, Kaur G, Seyedsalehi A et al (2020) Progress in 3D bioprinting technology for tissue/organ regenerative engineering. Biomaterials 226:119536. https://doi.org/10.1016/j.biomaterials. 2019.119536

7. Ma Y, Ding P, Li L et al (2021) Three-dimensional printing for heart diseases: clinical application review. Bio Des Manuf 4(3):675-687. https://doi.org/10.1007/s42242-021-00125-8

8. Yan Q, Dong H, Su J et al (2018) A review of 3D printing technology for medical applications. Engineering 4(5):729-742. https:// doi.org/10.1016/j.eng.2018.07.021

9. Nadagouda MN, Rastogi V, Ginn M (2020) A review on 3D printing techniques for medical applications. Curr Opin Chem Eng 28:152-157. https://doi.org/10.1016/j.coche.2020.05.007

10. European Commission. Conformity assessment procedures for $3 \mathrm{D}$ printing and $3 \mathrm{D}$ printed products to be used in a medical context for COVID-19. 2020. https://ec.europa.eu/docsroom/documents/ 40562
11. Oladapo BI, Ismail SO, Afolalu TD et al (2021) Review on 3D printing: fight against COVID-19. Mater Chem Phys 258:123943. https://doi.org/10.1016/j.matchemphys.2020.123943

12. Ventola CL (2014) Medical applications for 3D printing: current and projected uses. Pharm Ther 39(10):704-711

13. What is medical 3D printing - and how is it regulated. https://www. pewtrusts.org/zh/research-and-analysis/issue-briefs/2020/10/ what-is-medical-3d-printing-and-how-is-it-regulated. Accessed 5 Sept 2021

14. 3D opportunity for health care: demystifying FDA regulations for medical devices. https://www2.deloitte.com/us/en/insights/focus/ 3d-opportunity/additive-manufacturing-fda-regulations-medicaldevices.html. Accessed 5 Sept 2021

15. Christensen A, Rybicki FJ (2017) Maintaining safety and efficacy for 3D printing in medicine. 3D Print Med 3(1):1. https://doi.org/ 10.1186/s41205-016-0009-5

16. Ricles LM, Coburn JC, Di Prima M et al (2018) Regulating 3D-printed medical products. Sci Transl Med 10(461):eaan6521. https://doi.org/10.1126/scitranslmed.aan6521

17. Martelli N, Serrano C, van den Brink H et al (2016) Advantages and disadvantages of 3-dimensional printing in surgery: a systematic review. Surgery 159(6):1485-1500. https://doi.org/10.1016/j.surg. 2015.12.017

18. Choy WJ, Mobbs RJ, Wilcox B et al (2017) Reconstruction of thoracic spine using a personalized 3D-printed vertebral body in adolescent with T9 primary bone tumor. World Neurosurg 105:1032.e13-1032.e17. https://doi.org/10.1016/j.wneu.2017.05. 133

19. Jin Z, Li Y, Yu K et al (2021) 3D printing of physical organ models: recent developments and challenges. Adv Sci. https://doi.org/10. 1002/advs.202101394

20. Li J, Cui X, Hooper GJ et al (2020) Rational design, biofunctionalization and biological performance of hybrid additive manufactured titanium implants for orthopaedic applications: a review. J Mech Behav Biomed Mater 105:103671. https://doi.org/ 10.1016/j.jmbbm.2020.103671

21. Horst A, McDonald F (2020) Uncertain but not unregulated: medical product regulation in the light of three-dimensional printed medical products. 3D Print Addit Manuf 7(5):248-257. https://doi. org/10.1089/3dp.2020.0076

22. Dykema R (2019) Printing for the perfect fit: balancing FDA regulation of 3D printed medical devices. Wis L REv: 593. https:// heinonline.org/HOL/Page?handle=hein.journals/wlr2019\&id= $605 \&$ collection $=$ journals \&index $=$

23. Tavassoli S, Brandt M, Qian M et al (2020) Adoption and diffusion of disruptive technologies: the case of additive manufacturing in medical technology industry in Australia. Procedia Manuf 43:18-24. https://doi.org/10.1016/j.promfg.2020.02.103

24. Wu J, Liu B (2020) Overview of domestic and foreign regulatory regulations about customized additive manufacturing medical devices and considerations of the industry development. Orthop Biomech Mater Clin Study 17(05):65-70 (in Chinese)

25. Luo L, Yu S, Yu Z et al (2015) The advantage and clinical application of titanium medical devices prepared by 3D printing. Orthop Biomech Mater Clin Study 12(06):72-75 (in Chinese)

26. Colpani A, Fiorentino A, Ceretti E (2018) 3D printing for health \& wealth: fabrication of custom-made medical devices through additive manufacturing. In: Proceedings of 21 st international esaform conference on material forming (Esaform 2018), Article 140006. https://doi.org/10.1063/1.5034998

27. McDonald J (2019) Regulatory considerations for devices manufactured using additive manufacturing technologies. In: Devine DM (ed) Polymer-based additive manufacturing. Springer, Switzerland, pp 243-254 
28. Technical considerations for additive manufactured devices: guidance for industry and food and drug administration staff. US Food and Drug Administration. 2017

29. Zhang S, Min Y, Sun J et al (2017) Introduction and considerations of the US FDA guidance about technical considerations for additive manufactured device. China Med Device Inform 23(19):1-2 (in Chinese)

30. European commission. Guidance note for manufacturers of custom-made medical devices. 2009

31. IMDRF. About IMDRF. Accessed 5 Sept 2021

32. Min Y, Zhang J, Liu B et al (2021) Discussion on technical review guidance for registration of personalized additive manufacturing medical devices of passive implantable bone, joint and oral hard tissues. Chin J Med Instrum 45(2):200-204. https://doi.org/10.3969/ j.issn.1671-7104.2021.02.016 (in Chinese)

33. Min Y, Zhou W, Pan S et al (2019) Interpretation of personalized medical device terms published by IMDRF. Chin Pharm Aff 33(01):41-44 (in Chinese)

34. Schuh JCL, Funk KA (2019) Compilation of international standards and regulatory guidance documents for evaluation of biomaterials, medical devices, and 3-D printed and regenerative medicine products. Toxicol Pathol 47(3):344-357. https://doi.org/10.1177/ 0192623318804121

35. Class III medical devices subject to clinical trial approval. National Medical Products Administration. 2020

36. National plan for promoting the development of additive manufacturing industry (2015-2016). Ministry of Industry and Information Technology of the People's Republic of China. Accessed 7 Dec 2021

37. Action plan for the development of additive manufacturing industry (2017-2020). Ministry of Industry and Information Technology of the People's Republic of China. Accessed 7 Dec 2021

38. Guidelines for the technical review of the registration of customized additive manufacturing medical devices (draft for comments). Center for Medical Device Evaluation of China National Medical Products Administration. Accessed 7 Dec 2021

39. Regulations on the management of customized medical devices (trial). National Medical Products Administration. 2019

40. Custom device exemption: guidance for industry and food and drug administration staff. US Food and Drug Administration. 2014

41. Guidelines for the technical review of the registration of passive implantable bone, joint and oral hard tissue personalized additive manufacturing medical devices (No. 70 of 2019). National Medical Products Administration. Accessed 7 Dec 2021

42. Introduction to the additive manufacturing medical devices committee of china association for medical devices industry. AMMDC of China Association for Medical Devices Industry. Accessed 7 Dec 2021

43. The first batch of group standards for 3D printed medical devices. Additive Manufacturing Medical Devices Committee. Accessed 7 Dec 2021

44. The second batch of group standards for 3D printed medical devices. Additive Manufacturing Medical Devices Committee. Accessed 7 Dec 2021

45. The third batch of group standards for 3D printed medical devices. Additive Manufacturing Medical Devices Committee. Accessed 7 Dec 2021

46. Guidelines for the technical review of the registration of equivalence models of customized personalized bone implants. National Medical Products Administration. 2020

47. Morrison RJ, Kashlan KN, Flanangan CL et al (2015) Regulatory considerations in the design and manufacturing of implantable 3Dprinted medical devices. Clin Transl Sci 8(5):594-600. https://doi. org/10.1111/cts. 12315
48. Di Prima M, Coburn J, Hwang D et al (2016) Additively manufactured medical products - the FDA perspective. 3D Print Med 2:Article 1. https://doi.org/10.1186/s41205-016-0005-9

49. Weadock WJ (2020) Quality control in medical 3D pinting. Acad Radiol 27(5):661-662. https://doi.org/10.1016/j.acra.2019.11.001

50. Sun J, Guo X, Liu B et al (2020) Research on quality control and technology evaluation of personalized orthopedic implant medical devices. Orthop Biomech Mater Clin Study 17(03):66-69 (in Chinese)

51. Han Q, Huang D, Yang J et al (2019) Component elements and control methods of the whole process of medical and manufacturing interaction for the customized and personalized additional manufacturing medical devices. Chin Pharm Aff 33(12):1438-1443 (in Chinese)

52. Han Q, Li M, Wang C et al (2018) The progress of standardization and quality control of additive manufacturing medical device. $\mathbf{J}$ Tissue Eng Reconstr Surg 14(03):121-122 (in Chinese)

53. Sing SL (2019) Introduction to additive manufacturing for orthopaedic implants. Selective laser melting of novel titaniumtantalum alloy as orthopaedic biomaterial. Springer, Singapore, pp $1-8$

54. Sudarmadji N, Tan JY, Leong KF et al (2011) Investigation of the mechanical properties and porosity relationships in selective laser-sintered polyhedral for functionally graded scaffolds. Acta Biomater 7(2):530-537. https://doi.org/10.1016/j.actbio.2010.09. 024

55. Liang H, Yang Y, Xie D et al (2019) Trabecular-like Ti-6Al-4V scaffolds for orthopedic: fabrication by selective laser melting and in vitro biocompatibility. J Mater Sci Technol 35(7):1284-1297. https://doi.org/10.1016/j.jmst.2019.01.012

56. Kulkarni M, Mazare A, Schmuki P et al (2014) Biomaterial surface modification of titanium and titanium alloys for medical applications. Nanomedicine 111:111-136

57. Pobloth AM, Checa S, Razi H et al (2018) Mechanobiologically optimized 3D titanium-mesh scaffolds enhance bone regeneration in critical segmental defects in sheep. Sci Transl Med. https://doi. org/10.1126/scitranslmed.aam8828

58. Guo X, Lu Z, Liu B (2018) The pre-market clinical evaluation and requirement on post-market study of individualized anatomymatching bone prosthesis. Orthop Biomech Mater Clin Study 15(04):77-80 (in Chinese)

59. Xu X, Shi Y, Yan X (2017) Research on quality control point of medical instrument by additive manufacturing (3D Printing). China Med Device Inf 23(19):6-7 (in Chinese)

60. 2020 Medical Device Safety Promotion Week. National medical products administration. Accessed 7 Dec 2021

61. Zhang S, Sun J, Chen C et al (2018) Development and application of orthopaedic medical devices by addictive manufacturing. Orthop Biomech Mater Clin Study 15(01):76-80 (in Chinese)

62. Adamo JE, Grayson WL, Hatcher H et al (2018) Regulatory interfaces surrounding the growing field of additive manufacturing of medical devices and biologic products. J Clin Transl Sci 2(5):301-304. https://doi.org/10.1017/cts.2018.331

63. Willemsen K, Nizak R, Noordmans HJ et al (2019) Challenges in the design and regulatory approval of 3D-printed surgical implants: a two-case series. Lancet Digit Health 1(4):e163-e171. https://doi. org/10.1016/s2589-7500(19)30067-6

64. Yang Q, Gao B, Xu F (2020) Recent advances in 4D bioprinting. Biotechnol J 15(1):e1900086. https://doi.org/10.1002/biot. 201900086

65. Gao B, Yang Q, Zhao X et al (2016) 4D bioprinting for biomedical applications. Trends Biotechnol 34(9):746-756. https://doi.org/10. 1016/j.tibtech.2016.03.004 
66. Zhang B, Luo Y, Ma L et al (2018) 3D bioprinting: an emerging technology full of opportunities and challenges. Bio Des Manuf 1(1):2-13. https://doi.org/10.1007/s42242-018-0004-3

67. Wang Y, Guo Y, Wei Q et al (2021) Current researches on design and manufacture of biopolymer-based osteochondral biomimetic scaffolds. Bio Des Manuf 4(3):541-567. https://doi.org/10.1007/ s42242-020-00119-y

68. Murphy SV, Atala A (2014) 3D bioprinting of tissues and organs. Nat Biotechnol 32(8):773-785. https://doi.org/10.1038/nbt.2958

69. Gilbert F, O'Connell CD, Mladenovska T et al (2018) Print me an organ? Ethical and regulatory issues emerging from 3D bioprinting in medicine. Sci Eng Ethics 24(1):73-91. https://doi.org/10.1007/ s11948-017-9874-6

70. Shao L, Gao Q, Xie C et al (2020) Sacrificial microgel-laden bioinkenabled 3D bioprinting of mesoscale pore networks. Bio Des Manuf 3(1):30-39. https://doi.org/10.1007/s42242-020-00062-y
71. Gao Q, Zhao P, Zhou R et al (2019) Rapid assembling organ prototypes with controllable cell-laden multi-scale sheets. Bio Des Manuf 2(1):1-9. https://doi.org/10.1007/s42242-019-00032-z

72. Xie M, Gao Q, Fu J et al (2020) Bioprinting of novel 3D tumor array chip for drug screening. Bio Des Manuf 3(3):175-188. https://doi. org/10.1007/s42242-020-00078-4

73. Varkey M, Atala A (2015) Organ bioprinting: a closer look at ethics and policies. Wake For JL Pol'y 5:275

74. Villar G, Graham AD, Bayley H (2013) A tissue-like printed material. Science 340(6128):48-52. https://doi.org/10.1126/science. 1229495

75. Vijayavenkataraman S, Lu WF, Fuh JYH (2016) 3D bioprinting - an ethical, legal and social aspects (ELSA) framework. Bioprinting 1-2:11-21. https://doi.org/10.1016/j.bprint.2016.08. 001 